\title{
Experimental assessment of failure criteria for the interaction of normal stress perpendicular to the grain with rolling shear stress in Norway spruce clear wood
}

\author{
Shaheda T. Akter ${ }^{1} \cdot$ Thomas K. Bader $^{1}[$ \\ Received: 6 December 2019 / Published online: 27 August 2020 \\ (c) The Author(s) 2020
}

\begin{abstract}
The anisotropic material behavior of wood, considered as a cylindrically orthotropic material with annual rings, leads to several different failure mechanisms already under uniaxial stresses. Stress interaction becomes important in the engineering design of structural elements and is often predicted by failure criteria based on uniaxial properties. The prediction quality of failure criteria has been assessed with longitudinal shear stress interaction, though less is known on rolling shear stress in interaction with stress perpendicular to the grain. The study aims at investigating the corresponding mechanical behavior of Norway spruce (Picea abies) clear wood by validating failure envelopes for stress combinations in the cross-sectional plane, based on experimental investigations. For this purpose, a test setup that controls the stress interaction and loading of clear wood along pre-defined displacement paths needed to be developed. Experimentally defined failure states could then be compared to failure surfaces predicted by the phenomenological failure criteria. Material behavior was quantified in terms of stiffness, strength, and elastic and post-elastic responses on dog-bone shaped specimens loaded along 12 different displacement paths. A comparison with failure criteria for two nominal compressive strain levels showed that a combination of failure criteria would be required to represent the material behavior and consider the positive effect of compressive stresses on the rolling shear strength. The findings of this work will contribute to studying local stress distribution of structural elements and construction details, where stress interactions with rolling shear develop.
\end{abstract}

\section{Introduction}

Multiaxial and complex stress states can arise in timber structures depending on the position and direction of the applied force with regards to the wood grain direction. This requires special attention due to the material's anisotropy as a consequence of its heterogeneous and porous microstructure (Kollmann et al. 2012). In particular on the material scale, where the local material orientations are commonly different from the global specimen geometry and loading, multiaxial stress states occur. The annual ring structure in a radial ( $\mathrm{R}$ )-tangential $(\mathrm{T})$ cross-section of wood that is loaded by uniform compression perpendicular to the grain leads to a non-uniform stress state and combination of normal stresses in the $\mathrm{R}$ and $\mathrm{T}$ direction with rolling shear. Compression

Thomas K. Bader

thomas.bader@1nu.se

1 Department of Building Technology, Linnaeus University, 35295 Växjö, Sweden perpendicular to the grain, such as a macroscopic phenomenon in timber engineering, and the influence of boundary conditions have been studied extensively by Hall (1980), Hoffmeyer et al. (2000), Blass and Görlacher (2004), Bleron et al. (2011), Leijten et al. (2012) and Gehri (1997). Phenomenological models for the engineering design have been developed by Madsen et al. (1982), Van der Put (2008), EN 1995-1-1 (2004) and Lathuilliere et al. (2015). However, on the local material scale, the interaction of stresses in the principal material directions should be considered, though reliable test data and validated design formulas are missing. The interaction of stresses perpendicular to the grain with rolling shear also has a significant role in the failure of cross-laminated, engineered wood-based products (Ehrhart and Brandner 2018). The very low value of the rolling shear modulus, which is as low as one-tenth to one-twentieth of the perpendicular to the grain modulus of elasticity, is a consequence of the anatomical and inhomogeneous, fibrous structure of wood.

The design of structural elements made from engineering wood-based products, connections, beam elements with 
holes and notches, etc. demands special attention in terms of material behavior under stress interaction. A failure envelope that can predict the strength of wood for such combinations of stresses is essential for reliable design. It should even consider the compression-tension asymmetry in combination with shear stresses (Steiger and Gehri 2011). Threedimensional anisotropic phenomenological failure criteria have been proposed for this purpose. However, these merely describe the phenomenon of failure, but neither the material behavior nor the failure mechanism (Cabrero et al. 2012; Kasal and Leichti 2005). Most of these phenomenological failure criteria were developed for composite materials based on isotropic failure criteria. The validation of these anisotropic failure criteria for stress interaction in natural orthotropic materials such as wood has attracted less attention, especially for the combinations with rolling shear stresses.

The aim of this paper is to investigate the mechanical behavior of clear wood under stresses perpendicular to the grain in interaction with rolling shear stresses. More specifically, the objective of this study is to validate failure envelopes for this stress combination in Norway spruce (Picea abies), based on experimental investigations. For this purpose, it was necessary to develop a test setup that allows controlling the stress interaction and loading of clear wood along pre-defined displacement paths. The experimentally defined failure states could then be compared to failure surfaces predicted by the phenomenological failure criteria. Previous experimental, analytical, and theoretical research related to stress interaction with shear stresses is reviewed in Sect. 2, before the experimental setup, and the materials used in this study are described in Sect. 3. Section 4 presents and discusses the results and Sect. 5 concludes the paper.

\section{Experimental testing and analytical equations for stress interactions in wood}

Most data from the material properties determined through experiments and reported in the literature are related to the uniaxial material behavior of wood, though very limited research has been carried out to study the mechanical behavior of wood under biaxial or more complex stress states. The failure criteria for materials are mainly defined based on uniaxial strength properties, though to validate the stress interaction prediction of the failure criteria, biaxial testing of wood is required. Biaxial testing requires more advanced testing equipment to control and quantify the stress and strain state of the specimen. The literature reviewed here relates to both biaxial test setups and uniaxial shear testing devices, which are discussed and have been used to develop the test series in the R-T plane performed in this work.
Several uniaxial test setups for rolling shear testing of clear wood are available and have been developed to establish a uniform shear stress state in the most critical part of a test specimen. These test setups include the Iosipescu shear test (Iosipescu 1967; Dumail et al. 2000), the Arcan shear test (Arcan et al. 1978), the two-rail shear fixture (Melin 2008), the single cube apparatus (Hassel et al. 2009), and the off-axis shear fixture according to EN 408 (2010), which is a $14^{\circ}$ inclined compressive test where the force is applied at an inclination of $14^{\circ}$ to the shear plane or longitudinal axis of the specimen.

Magistris and Salmén $(2004,2005)$ investigated the scope of using the Wyoming version of the Iosipesco and Arcan shear fixtures by adding some extra features to obtain an interaction of stresses through a uniaxially applied force. Two rotating plates were added to the lower and upper parts of the Wyoming version of the Iosipesco shear fixture to change the ratio between shear stress and normal stress. They conducted a feasibility study of their in-house modified Iosipescu device, for pure shear and combined shear with compression interaction on orthotropic, medium density fiberboard, and Norway spruce solid wood. The experiments were carried out on $90^{\circ}$ notched specimens with a depth of $3.50 \mathrm{~mm}$, for small displacements, within the elastic limit.

A U-shaped fixture was added to the Arcan shear device to prevent movement as well as rotation of the specimen in the third direction (Stenberg 2002). Magistris and Salmén (2005) investigated the scope of using this in-house modified Arcan device for a comparatively thick wood specimen in the case of combined loading. After finding the device suitable for combined loading in wood, they used the setup to study the deformation pattern of wet wood fibers (Norway spruce) in the longitudinal (L)-tangential (T) plane at an elevated temperature of $50{ }^{\circ} \mathrm{C}$ and $90^{\circ} \mathrm{C}$, under compression, shear, and combined compression with shear loading. The device was even used for repeated loading to study the energy consumption required to collapse the wood cells under different loading combinations and repeated loading. The specimen size was $2 \times 40 \times 15 \mathrm{~mm}^{3}$ (R, T, and L directions).

Even though, the setups developed by Magistris and Salmén (2004) were found suitable for biaxial testing in proof-of-concept tests, they did not allow for the direct control and quantification of the displacements and forces in two orthogonal directions, which makes the derivation of a failure envelope difficult.

Spengler (1982) performed a study on Norway spruce glued-laminated timber (glulam) specimens that were subjected to the combination of stress perpendicular to the grain with shear in L-R plane. He used L-shaped steel plates to apply loading on a rectangular shaped specimen in two perpendicular directions. The specimens had a length of $220 \mathrm{~mm}$, a width of $80 \mathrm{~mm}$ to $140 \mathrm{~mm}$ and a thickness of 22 to $33 \mathrm{~mm}$, and were adhesive-bonded with the steel plates. 


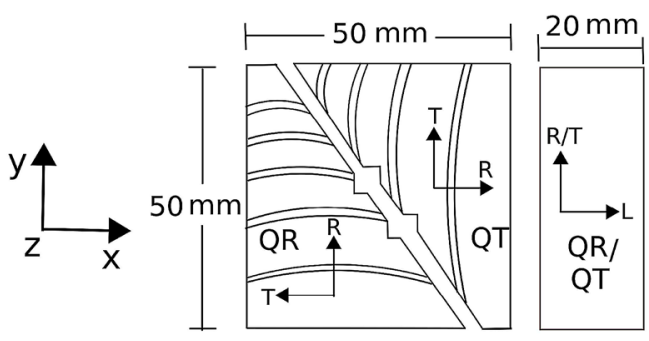

(a)

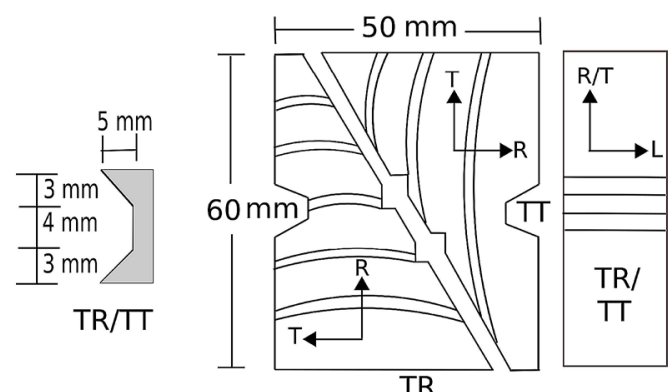

(c)

$T$

ST-45

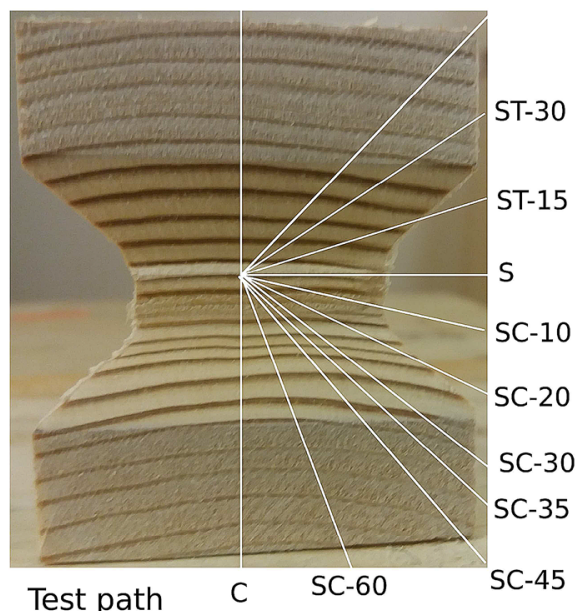

(e)

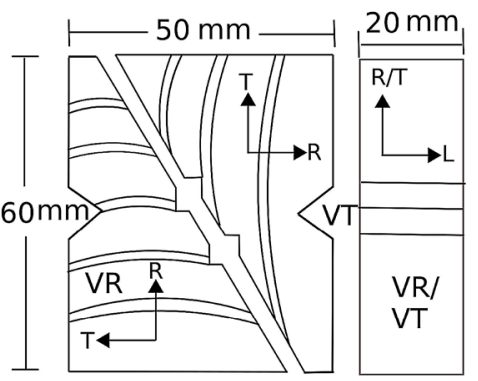

(b)

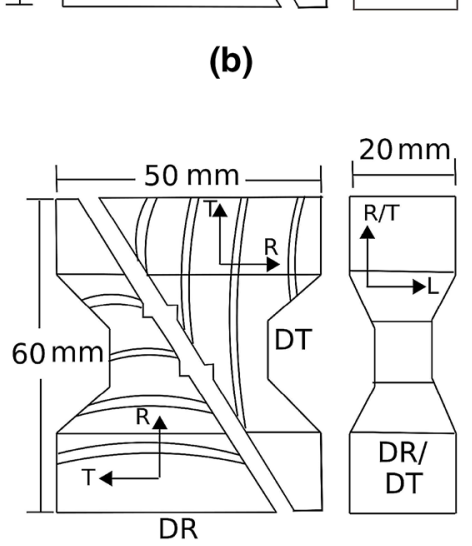

(d)

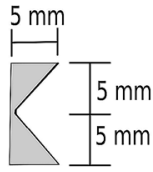

VR/VT

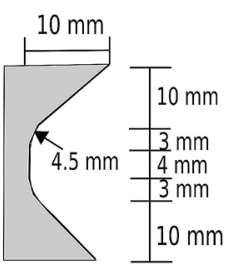

DR/DT Front

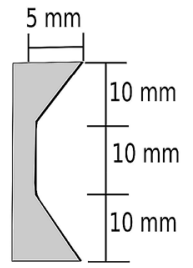

DR/DT Side

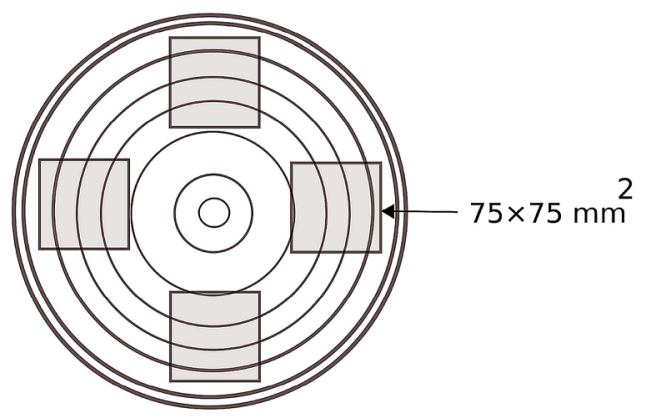

(f)

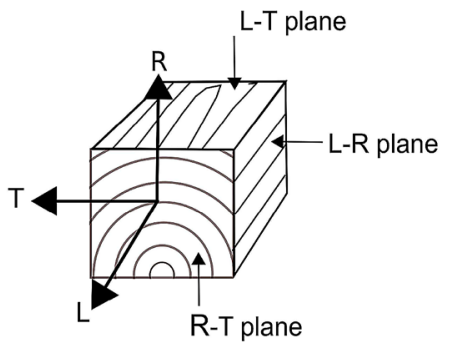

(g)

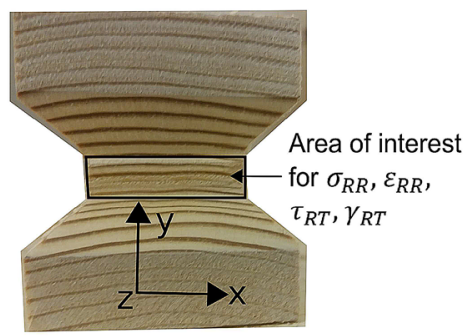

(h) RT-(R) orientation

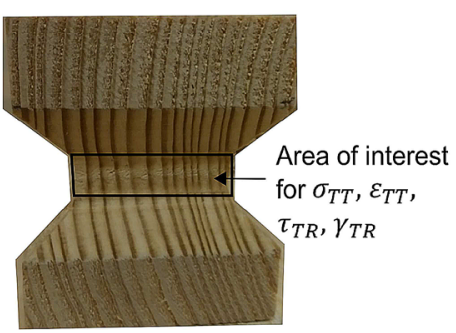

(i) $T R-(T)$ orientation

Fig. 1 Specimen's shape and dimensions a Q-type, b V-type, c T-type, $\mathbf{d}$ D-type, e illustration of displacement paths for uniaxial and biaxial testing; f specimen's origin; $\mathbf{g}$ principal material axes; test orientations with corresponding stresses and strains $\mathbf{h}$ R-orientation, $\mathbf{i}$ T-orientation 
The setup was comparably simple, but required gluing of the specimens. Without a continuous force transmission through the adhesive bond, however, it would lead to stress concentrations in the corner points, which could be problematic particularly when studying the R-T plane with lower stiffness properties and different Young's modulus to shear modulus ratios.

Phenomenological failure criteria generally describe a surface in the six-dimensional stress space represented by mathematical expressions. Most of the anisotropic strength criteria are based on isotropic yield criteria (Cabrero et al. 2012), of which only a few are developed for wood. This work focuses on the in-plane interaction of stresses perpendicular to the grain with rolling shear stress, and the corresponding failure criteria can be illustrated in a $2 \mathrm{D}$ representation.

In the case of uniaxial stress, a material fails when the maximum normal stress or shear stress reaches the corresponding strength value. When considering stresses parallel to the anatomical directions of wood, the maximum stress criterion in the R-T plane can be expressed as

$\frac{\sigma_{R R}}{f_{R}}=1$,

$\frac{\sigma_{T T}}{f_{T}}=1$,

$\frac{\tau_{R T}}{f_{v, R T}}=1$,

where $\sigma_{R R}$ and $\sigma_{T T}$ are the normal stress components of the stress tensor $\sigma_{i j}$, in the corresponding material directions, $f_{R}$ is the strength in the radial direction, $f_{T}$ is the strength in the tangential direction, $\tau_{R T}$ is the rolling shear stress, and $f_{v, R T}$ is the rolling shear strength of wood.

For in-plane stress states in orthotropic materials, this uniaxial strength criterion can simply be extended to one, which considers orthotropic material properties and linear interaction (Aicher and Klöck 2001). For stresses in the R-T plane of wood this reads as

$\frac{\sigma_{R R}}{f_{R}}+\frac{\sigma_{T T}}{f_{T}}+\frac{\tau_{R T}}{f_{v, R T}}=1$.

The widely used Hankinson (1921) formula to determine the strength, $f_{\theta}$, of wood loaded under an angle $\theta$ to the grain was derived from a linear strength criterion. The Hankinson's formula can be expressed as

$f_{\theta}=\frac{f_{L} \cdot f_{\overline{R T}}}{f_{L} \cdot \sin ^{n} \theta+f_{\overline{R T}} \cdot \cos ^{n} \theta}$, where $f_{L}$ is the strength parallel to the grain and $f_{\overline{R T}}$ is the strength perpendicular to the grain. $f_{\overline{R T}}$ is used in engineering applications as an effective strength perpendicular to the grain, which could be replaced by the strengths in the radial or tangential direction. In general, $n=2$ is used for compressive strength and $n=1.5$ is used for tensile strength (Mascia and Simoni 2013).

The simplest quadratic criterion resulting in an ellipsoidal failure surface for in-plane stress states in R-T plane can be written as

$\left(\frac{\sigma_{R R}}{f_{R}}\right)^{2}+\left(\frac{\sigma_{T T}}{f_{R}}\right)^{2}+\left(\frac{\tau_{R T}}{f_{v, R T}}\right)^{2}=1$,

and would allow for exploitation of a larger stress space compared to the linear interaction criterion given in Eq. (4).

The von Mises strength criterion is based on the maximum distortional energy theory. It assumes that the hydrostatic part of the stress tensor does not contribute to the yielding of the material. The von Mises criterion is given as

$\left(\frac{\sigma_{R R}}{f_{R}}\right)^{2}-\frac{\sigma_{R R} \sigma_{T T}}{f_{R} f_{T}}+\left(\frac{\sigma_{T T}}{f_{T}}\right)^{2}+3\left(\frac{\tau_{R T}}{f_{v, R T}}\right)^{2}=1$.

This criterion includes an interaction term between the normal stresses that is not included in the quadratic failure criterion in Eq. (6). This interaction term affects the shape of the failure envelope. The von Mises criterion is applicable to materials that exhibit metal-like plasticity, but not to wood.

Hill (1950) extended the von Mises strength theory by considering that a material behaves anisotropic when plasticity occurs. For plane stress states, the criterion reads as

$$
\begin{gathered}
\left(\frac{\sigma_{R R}}{f_{R}}\right)^{2}-\sigma_{R R} \sigma_{T T}\left(\frac{1}{f_{R}^{2}}+\frac{1}{f_{T}^{2}}-\frac{1}{f_{L}^{2}}\right) \\
+\left(\frac{\sigma_{T T}}{f_{T}}\right)^{2}+\left(\frac{\tau_{R T}}{f_{v, R T}}\right)^{2}=1 .
\end{gathered}
$$

Later on, Azzi and Tsai (1965) adopted this criterion to the case of transversely isotropic composite materials. This criterion is known as Tsai-Hill criterion and for plane stress states, it can be expressed as

$\left(\frac{\sigma_{R R}}{f_{R}}\right)^{2}-\left(\frac{\sigma_{R R} \sigma_{T T}}{f_{R}^{2}}\right)+\left(\frac{\sigma_{T T}}{f_{T}}\right)^{2}+\left(\frac{\tau_{R T}}{f_{v, R T}}\right)^{2}=1$.

This criterion has been applied to a number of applications in timber engineering problems (Cabrero et al. 2012; Mascia and Simoni 2013).

One of the first strength criteria for wood was formulated by Norris (1962), who postulated that failure of the material would happen if any one of the following three equations are satisfied, 
$\left(\frac{\sigma_{R R}}{f_{R}}\right)^{2}-\frac{\sigma_{R R} \sigma_{T T}}{f_{R} f_{T}}+\left(\frac{\sigma_{T T}}{f_{T}}\right)^{2}+\left(\frac{\tau_{R T}}{f_{v, R T}}\right)^{2}=1$

$\left(\frac{\sigma_{R R}}{f_{R}}\right)^{2}=1$

$\left(\frac{\sigma_{T T}}{T}\right)^{2}=1$

The only difference between the von Mises criterion in Eq. (7) and the Norris criterion in Eq. (10) is the factor, which multiplies with the shear term. Hence, it gives the same surface as von Mises in a normal stress plane, but a different surface when considering the interaction between normal and shear stress.

All of the above-mentioned anisotropic failure criteria consider the tensile and compressive strength of a material to be the same, which is not the case for wood. Note, for plane stress states for the herein considered combination of normal and shear stress, Quadratic, Tsai-Hill, Hill, and Norris failure criteria reduce to the same limit curve.

Hoffman (1967) proposed a failure criterion based on Hill's criterion, accounting for the difference between the tensile and compressive strength of the material, $f_{c, R}$ for $\sigma_{R R}<0, f_{t, R}$ for $\sigma_{R R}>0$ and $f_{c, T}$ for $\sigma_{T T}<0, f_{t, T}$ for $\sigma_{T T}>0$. It was originally formulated as a quadratic function (Schellekens and De Borst 1990) with nine independent variables. By substituting the material coefficients determined from experiments, Hoffman's failure criterion for plane stress can be written as

$$
\begin{aligned}
& \left(\frac{\sigma_{R R}^{2}}{f_{t, R} f_{c, R}}\right)+\left(\frac{\sigma_{T T}^{2}}{f_{t, T} f_{c, T}}\right)-\left(\frac{\sigma_{R R} \sigma_{T T}}{f_{t, R} f_{c, R}}\right)+\left(\frac{\tau_{R T}^{2}}{f_{v, R T}^{2}}\right) \\
& \quad+\sigma_{R R} \frac{f_{c, R}-f_{t, R}}{f_{t, R} f_{c, R}}+\sigma_{T T} \frac{f_{c, T}-f_{t, T}}{f_{t, T} f_{c, T}}=1,
\end{aligned}
$$

where the index ${ }_{t}$ indicates the tensile strength properties and ${ }_{c}$ indicates the compressive strength properties. This criterion has been widely used in the ductile failure in metals, as well as for brittle failure in fibrous materials like wood (Mascia and Simoni 2013).

Tsai and $\mathrm{Wu}$ (1971) proposed a considerably more versatile tool to handle multi-axial stress states, and thus the combination of normal stresses with shear stresses, in terms of strength tensors in polynomial form. This criterion is an invariant to coordinate transformation. It can be represented in index notation as

$F_{i j} \sigma_{i j}+F_{i j k l} \sigma_{i j} \sigma_{k l}=1$,

where $F_{i j}$ is the second order strength tensor and $F_{i j k l}$ is the fourth order strength tensor. The equation can be written in expanded form for plane stress conditions in the R-T plane as

$$
\begin{gathered}
F_{R R} \sigma_{R R}+F_{T T} \sigma_{T T}+F_{R R R R} \sigma_{R R}^{2}+F_{T T T T} \sigma_{T T}^{2} \\
+2 F_{R R T T} \sigma_{R R} \sigma_{T T}+F_{R T R T} \tau_{R T}^{2}=1
\end{gathered}
$$

where the coefficients are defined as

$F_{R R}=\frac{1}{f_{t, R}}-\frac{1}{f_{c, R}}$,

$F_{T T}=\frac{1}{f_{t, T}}-\frac{1}{f_{c, T}}$

$F_{R R R R}=\frac{1}{f_{t, R} f_{c, R}}$,

$F_{T T T T}=\frac{1}{f_{t, T} f_{c, T}}$,

$F_{R R T T}=F_{R R T T}^{*} \sqrt{\frac{1}{f_{t, R} f_{c, R} f_{t, T} f_{c, T}}}$,

$F_{R T R T}=\frac{1}{f_{v, R T}^{2}}$.

Compared to the other failure criteria discussed above, the Tsai-Wu criterion includes an interaction coefficient, $F_{R R T T}$, that is independent of uniaxial strength values. A prior biaxial experiment is required to determine the value of this interaction term. In other failure criteria like Hill, Tsai-Hill, Norris, and Hoffman, the stress interaction term was defined from uniaxial strength values only. For stability conditions and to get a closed failure surface the following condition has to be fulfilled

$F_{\text {RRRR }} F_{\text {TTTT }}-F_{\text {RRTT }}^{2} \geq 0$,

which consequently limits the interaction term to $-1 \leq F_{R R T T}^{*} \leq 1$.

Kasal and Leichti (2005) mentioned that this term can be defined in several ways depending on the testing procedure of generating the biaxial stress state. Hence, different researchers have used different methods to account for this interaction. According to Kasal and Leichti (2005), another interaction term involving shear stress should also be considered in Eq. (15). They state the difficulties of determining this interaction coefficient as a reason for omitting additional shear interaction terms.

Eberhardsteiner (2013) carried out numerous biaxial experiments on clear wood of Norway spruce in the L-R plane, which were subjected to two orthogonal normal stresses for the different load to grain angles. Cruciform Norway spruce test specimens were displacement-loaded 
along different displacement paths, prescribing different ratios of the orthogonal displacements. Tests were performed with different grain angles in the test specimen, which led to numerous investigated stress states with shear in the L-R plane. The point corresponding to the initial maximum stress value (Mackenzie-Helnwein et al. 2003) of any of the global normal stresses was considered as material failure. The obtained failure envelope revealed an elliptical surface that agrees well with the elliptical failure criteria, though this kind of phenomenological failure criterion was unable to distinguish between different failure modes. The experiments included even pure shear stress in the L-R plane, which was obtained for a grain angle of $45^{\circ}$ and a displacement ratio of 1:1. Based on these experiments, Mackenzie-Helnwein et al. (2003) defined a multi-surface orthotropic failure criterion in plane-stress that considered four surfaces for four failure modes; namely for tensile or brittle failure mode in the fiber direction, brittle tensile failure mode in perpendicular to the grain direction, parallel to the grain compression failure mode, and ductile failure mode in compression perpendicular to the grain. The biaxial experimental data from Eberhardsteiner (2013) was further used by Cabrero et al. (2012) to validate some of the established phenomenological anisotropic failure criterion for wood in the L-R plane. The study showed that none of the failure criteria could predict a full failure envelope, but failure envelopes rather depend on biaxial stress-state, in terms of the combination of tensile stress, compressive stress or both. The best suited criteria in one stress-state could be the worst in another stress-state. For the first quadrant with tension parallel and perpendicular to the grain combination, the best-suited criteria were Cowin, Norris, and Tsai-Wu, whereas in the fourth quadrant, comprising of compression parallel to the grain and tension perpendicular to the grain, Norris and Cowin were the worst-fitting criteria. However, it remains unclear whether similar conclusions would be found in the R-T plane, which is the aim of this work.

Mascia and Simoni (2013) conducted a study of failure criteria, such as Hill, Tsai-Hill, Tsai-Wu, Hoffman, and Norris by comparing them to uniaxial and biaxial experimental tests carried out by Todeshini, cited in Mascia and Simoni (2013), on two Brazilian wood species, Pinus elliotti and Goupia glabra. The experiments were conducted to combine the compression parallel to the grain with the perpendicular to the grain stress, shear, and off-axis tensile test. The investigation showed that Tsai-Hill and Hoffman criteria fitted more adequately than other criteria for both species. They mentioned that the failure curves generated by Tsai-Wu, Tsai-Hill, and Hoffman differ significantly in the third (combined compression) and fourth (compression with tension) quadrant, but they were similar in the first (combined tension) and second quadrant (tension with compression). However, regarding failure surface for the combination of stress perpendicular to the grain with rolling shear, the investigation is limited to two quadrants, since with the combination of rolling shear with compression or with tension perpendicular to the grain, no distinction between positive and negative shear stresses is made.

Steiger and Gehri (2011) used the experimental results from Spengler (1982) and other sources, as well as their own shear tests on glulam beams to validate the SIA 265 design equation (SIA 265 2012), defining the strength for the combination of stress perpendicular to the grain with L-R shear stress. They state that the tension perpendicular to the grain and shear strength, as well as their interaction, are influenced by the size of the stressed-volume, as seen from the determination of the shear stiffness and strength of glulam beams. Good correlation was observed between the biaxial experiments by Spengler (1982) and the SIA 265 design equation. The latter is based on the assumption that

i the applicable shear stress is equal to the shear strength when the stress perpendicular to the grain is zero;

$\mathrm{j}$ shear stress reduces with increasing tensile stresses perpendicular to the grain and becomes zero when the tensile strength perpendicular to the grain is reached;

$\mathrm{k}$ shear stress can be increased above the pure shear strength, up to maximum applicable shear stress at the compressive strength perpendicular to the grain. A further increase in loading will induce crushing failure due to compression perpendicular to the grain.

The design equation is based on an elliptical failure criteria and is given below in R-T plane, for the range of $-f_{c, \overline{R T}} \leq \sigma_{\overline{R T}} \leq f_{t, \overline{R T}}$, with $f_{c, \overline{R T}}$ as the strength perpendicular to the grain in compression and $f_{t, \overline{R T}}$ as the strength perpendicular to the grain in tension.

$\left(\frac{f_{c, \overline{R T}}+\sigma_{\overline{R T}}}{f_{c, \overline{R T}}+f_{t, \overline{R T}}}\right)^{2}+\left(\frac{\tau_{R T}}{f_{v, R T}}\right)^{2}\left[1-\left(\frac{f_{c, \overline{R T}}}{f_{c, \overline{R T}}+f_{t, \overline{R T}}}\right)^{2}\right] \leq 1$,

where $\sigma_{\overline{R T}}$ is the stress perpendicular to the grain $\left(\sigma_{\overline{R T}}=\right.$ $\sigma_{t, \overline{R T}}$ in case of tensile stresses perpendicular to the grain and $\sigma_{\overline{R T}}=-\sigma_{c, \overline{R T}}$ in case of compressive stresses perpendicular to the grain), which in engineering applications as a simplification is not distinguished in radial and tangential directions but in design standards is rather specified as a tensile stress perpendicular to the grain $\sigma_{t, 90}$ or compressive stress perpendicular to the grain $\sigma_{c, 90}$. Note that this design equation is intended for application in timber engineering and commonly used with design values, with regards to material uncertainties. 


\section{Materials and methods}

\subsection{Norway spruce clear wood test specimens}

The mechanical behavior of Norway spruce (Picea abies) clear wood under stress perpendicular to the grain with rolling shear interaction was studied by means of an experimental setup. The material originates from the Experimental Forest and Research station in Asa, Sweden. The $\log$ of a Norway spruce tree was cut at $1.30 \mathrm{~m}$ and $2.70 \mathrm{~m}$ from the ground and sawn into pieces with cross-sectional dimensions of $75 \times 75 \mathrm{~mm}^{2}$, see Fig. 1 . The wood pieces were positioned so that one of the edges follows the same annual ring at the outer side of the log (Fig. 1) and four pieces with similar annual ring patterns could be cut out. The objective was to obtain homogeneous material properties and similar annual ring structure in all specimens without any knots or defects. The wood pieces were then dried in a research oven at Luleå University of Technology with a targeted equilibrium moisture content of $12 \%$. In the development of the test setup, geometry and setup effects on material behavior under compression, rolling shear and stress interaction in the R-T plane were studied. For this purpose, different shapes of specimens and different force imposing systems were investigated, as described in the following. Four different specimen geometries and shapes were cut out from the boards after drying, see Fig. 1,

Q quadratic specimens with a dimension of $50 \times 50 \mathrm{~mm}^{2}$ (width $\times$ height),

$\mathrm{V}$ V-notched specimens with a dimension of $50 \times 60 \mathrm{~mm}^{2}$,

$\mathrm{T}$ trapezoidal-notched specimens with a dimension of 50 $\times 60 \mathrm{~mm}^{2}$,

D dog-bone shaped specimens with a dimension of $50 \times$ $60 \mathrm{~mm}^{2}$.

All specimens had a length of $20 \mathrm{~mm}$ (in the longitudinal direction of wood), except for D-shaped specimens, which were $10 \mathrm{~mm}$ thick in the area of interest. Specimens were prepared with two orthogonal material orientations for testing with normal stresses in the radial (QR, VR, TR, DR) and the tangential (QT, VT, TT, DT) directions. Detailed notations and notch dimensions of the specimens are shown in Fig. 1. The prepared specimens were stored in a climate chamber at $20{ }^{\circ} \mathrm{C}$ room temperature and $65 \%$ relative humidity. Note that for the geometry and setup effect study, Q-type specimens were prepared from material at the east part of the stem, while, V-and T-type specimens were from the west side of the stem. The average density was $492 \mathrm{~kg} / \mathrm{m}^{3}$ for Q-type and $481 \mathrm{~kg} / \mathrm{m}^{3}$ for $\mathrm{V}$ - and T-type specimens. D-type specimens for loading in radial and tangential directions were prepared from material at the south and north side of the stem. The average density for the specimens of series DR was $490 \mathrm{~kg} / \mathrm{m}^{3}$ and DT was $508 \mathrm{~kg} / \mathrm{m}^{3}$. The average moisture content was $12.80 \%$, which was measured by means of the oven drying method. A total number of 104 specimens were tested of which 72 tests were performed on D-shaped specimens to compare experimental findings with analytical failure criteria. A total of 38 uniaxial tests were performed for rolling shear, uniaxial compression and tension perpendicular to the grain, to study the geometry and force imposing setup effects.

\subsection{Uniaxial and biaxial mechanical testing}

The mechanical test setup was developed within the test frame 322 of manufacturer MTS, which was equipped with two servo-hydraulic actuators (MTS Model 661.20F) with a capacity of $100 \mathrm{kN}$ for the vertical orientation and $50 \mathrm{kN}$ for the horizontal orientation.

Two different test setups, with basically two different force imposing systems, were used, see Fig. 2. Spengler's biaxial test setup (Spengler 1982) was considered as a basis to develop the setup, due to its very simple configuration that allows straight-forward testing, particularly when using it without adhesive bonding. The study on effects of the shape of specimens as described above was performed with this setup, consisting of two L-shaped steel blocks connected to the moveable sledges of the test frame, see Fig. 2a, d. The sledge below the test specimen is moveable in the horizontal direction, whereas the cross-head above the specimen is moveable in the vertical direction. Both are almost rigid, particularly when considering the weak stiffness of the test specimen. Q-, V-, and T-type specimens were then simply put into the test setup, which had $10 \mathrm{~mm}$ high steel plates on both sides of the bottom and the top of the L-shaped blocks to laterally support the specimens. There was a smooth surface on the side supports.

The force imposing system with L-shaped steel blocks is very simple, but could obviously lead to stress concentration at the corners. The wooden specimens could have been adhesively bonded to the steel supports in order to get a more distributed force transmission. However, this would have been very cumbersome and difficult to realize in this biaxial setup. Thus, mechanical grips were developed to more homogeneously introduce loading to the test specimens. For this purpose, the side support plates were replaced with mechanical grips using spiked steel plates with a height of $15 \mathrm{~mm}$, see Fig. 2c, e. The side support was fixed to the loading device while it was attached to the bolts and a fixed steel support on the other side of the test specimen. These mechanical grips allowed for the specimen to be grasped, while the pyramid texture of the steel plates gave a rough surface with high friction and good connection between the 


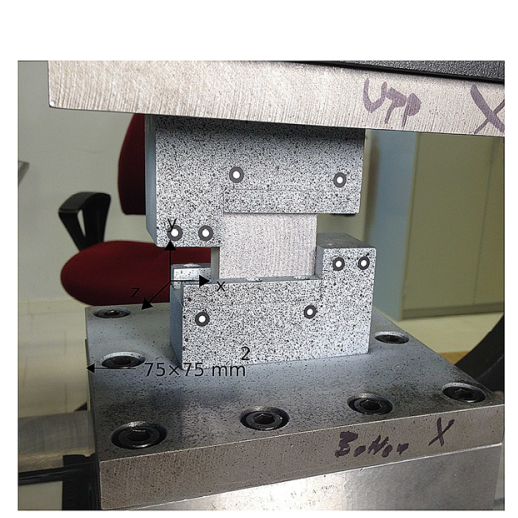

(a)

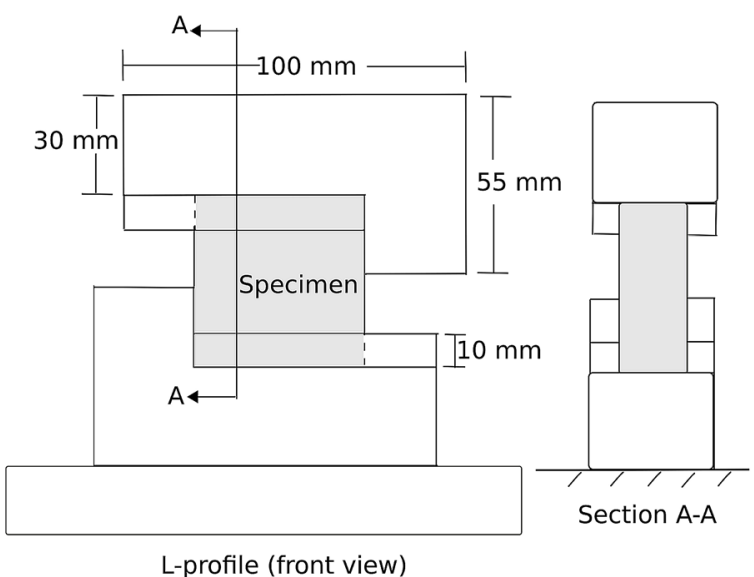

(d)

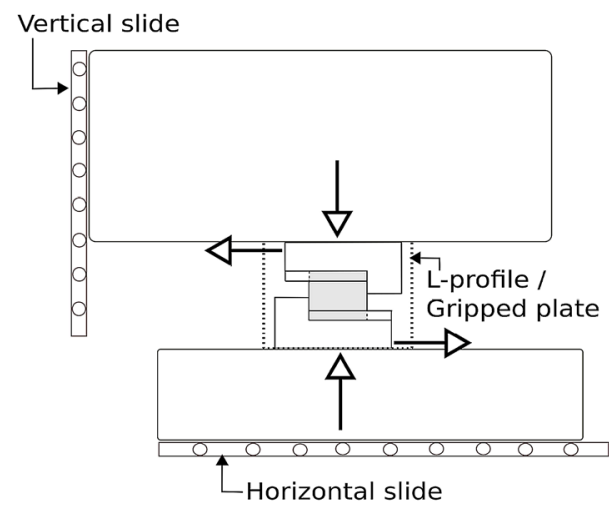

(b)

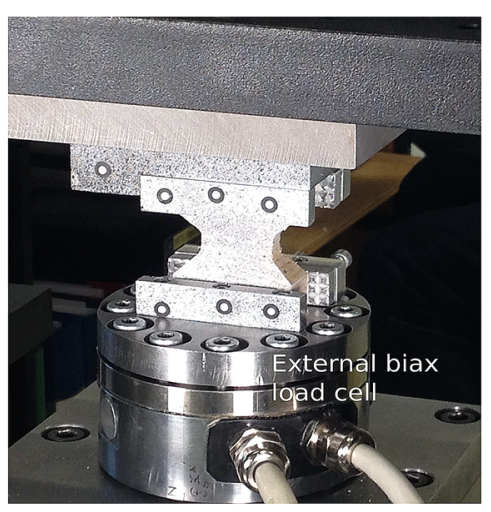

(c)

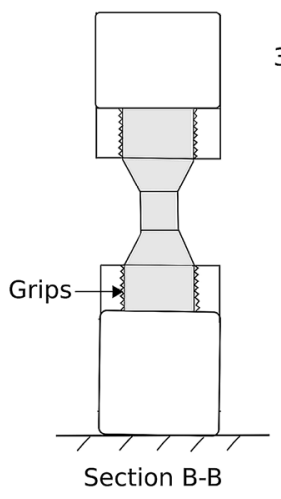

(e)

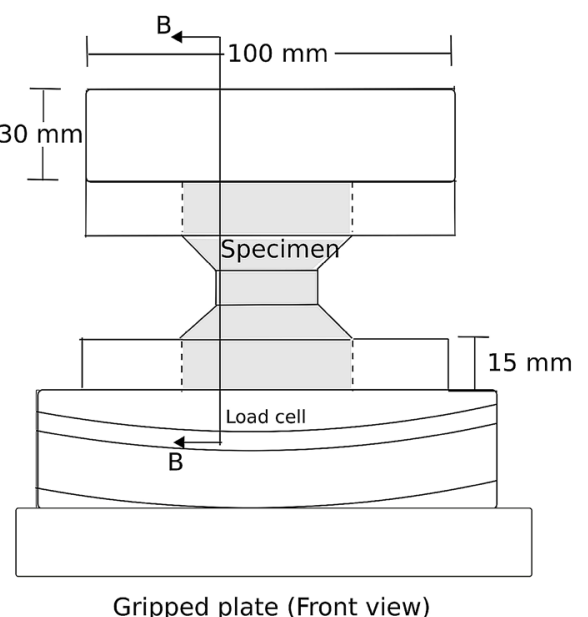

Gripped plate (Front view)

Fig. 2 Biaxial setups for loading of specimens with a L-shaped steel profile (L); b schematic drawing of the test setup and test frame; $\mathbf{c}$ mechanical grips (G) with position of external biaxial load cell; $\mathbf{d}$ dimensions of L-profile; e dimensions of G-plate

loading device and the wooden specimen. Dog-bone shaped specimens were tested in this device. The effects of the force imposing device on the stress and displacement state of the specimen could be studied by comparing the mechanical grips with the L-shaped steel block. Moreover, for this setup, an external multi-axial load cell of type GTM-00037 (Gassmann Thelss Messtechnik) with a capacity of $5 \mathrm{kN}$ in the vertical and the horizontal directions, the two directions evaluated in this study, was used to assess the accuracy of the larger in-built load cells in the loading range of the tests. A maximum difference of up to $12 \%$ between the in-built load cells and the external load cell was found, while the average difference for all tests was $6.5 \%$. The maximum difference was observed in the quasi-elastic part of the test at comparatively low forces, whereas the difference was less for higher forces. Only the results of the external load cell data are provided in the results section.

Experiments were carried out in displacement control mode along several displacement paths, as illustrated in Fig. 1e. Rolling shear combined with tension and compression stresses are denoted by ST and SC, followed by a number that is related to the angle with respect to the shear plane. A displacement rate of 2 or $1 \mathrm{~mm} / \mathrm{min}$ was applied in case of compression and biaxial tests and 0.50 or $1 \mathrm{~mm} /$ min in rolling shear tests. No influence of these displacement rates on the overall force-displacement behavior was observed. In the case of combined loading, with a certain ratio of vertical to horizontal displacement, displacements were applied simultaneously with an overall displacement rate equal to 1 or $2 \mathrm{~mm} / \mathrm{min}$. In addition, two unloading sequences were applied, one in the quasi-elastic and one in the elasto-plastic domain. The first unloading cycle was performed at a force of $1 \mathrm{kN}$, while the second unloading cycle was applied at a displacement of $5 \mathrm{~mm}$ for the compression and biaxial tests on D-type specimens. At the beginning and the end of each unloading cycle, the force (for the first unloading cycle) or displacement (for the second unloading cycle) was kept constant for $5 \mathrm{~s}$ to reduce the influence of time-dependent effects on the unloading stiffness. The investigated displacement paths for the corresponding test 
specimens are illustrated in Fig. 1. Two or three specimens were tested in each loading path. Corresponding forces and displacements were measured by the internal actuator of the MTS test frame and the external load cell.

Note that the lateral boundary condition plays an important role, which is most obvious in uniaxial testing. Displacement controlled testing as outlined above means constraining the lateral displacement, which as a consequence of the Poisson effect leads to a biaxial stress state. In addition to the displacement path testing, shear tests and compression tests with unconstrained lateral boundary conditions were performed. For unconstrained testing, the vertical or horizontal force was limited to a maximum absolute value of $50 \mathrm{~N}$, while the lateral displacements were not constrained. The latter test data was then compared to results from displacement-constrained loading to assess the effects on the determination of uniaxial mechanical properties.

A digital image correlation (DIC) system (Aramis, Gesellschaft für Optische Messtechnik mbH, Braunschweig, Germany) was used externally to measure the strain fields on the surface of the test specimens, as well as, through point markers, the displacements of the loading devices, during the experiments. This data allowed a comparison of the internal displacement measurement of the test frame with the optically determined displacement states. For DIC measurements, the specimens were sprayed with a very thin black speckle pattern on a very thin white base layer. The desired point size of the speckle pattern was 23 pixels (P). Two 12 MP cameras were used to continuously capture images at a rate of $1 \mathrm{~Hz}$ (one picture per second) in the elastic and the beginning of the elasto-plastic part, followed by a rate of $0.50 \mathrm{~Hz}$ (one picture every $2 \mathrm{~s}$ ) during the remaining test period. The field of view for the DIC was chosen to approximately $190 \times 140 \mathrm{~mm}^{2}$. A facet size of $19 \mathrm{P}$ together with a grid spacing of $15 \mathrm{P}$ (parameters have been set based on recommendations of the supplier and a preliminary study) resulted in a distance of approximately $1.20 \mathrm{~mm}$ between the measurement points. A noise study was carried out before each experiment to check the suitability of combining the speckle pattern, illumination, and camera settings. Displacements measured by the control system of the test frame were compared to displacements of point markers measured by DIC. The maximum difference was less than $10 \%$.

\subsection{Data evaluation and comparison with failure criteria}

The direct outputs of the tests were the displacement of the loading device as well as the load cell data, which were then used for the calculation of nominal engineering strains and stresses. The tensile or compressive strains, $\varepsilon_{R R}$ and $\varepsilon_{T T}$, were calculated as the vertical displacement of the force imposing device divided by the unsupported height of the specimen, which was $50 \mathrm{~mm}$ for Q-type specimens, and $60 \mathrm{~mm}$ for V-, T-, and D-type specimens with L-profile, while for the gripped plate it was $20 \mathrm{~mm}$ for Q- and 30 $\mathrm{mm}$ for $\mathrm{V}-$, $\mathrm{T}$-, and D-type specimens. Rolling shear strain, $\gamma_{R T}=2 \varepsilon_{R T}$ was determined as the horizontal displacement divided by the unsupported height of the specimens given above. For comparison reasons, average strains in the center of the specimens were even determined as the average strains on the surface of the specimens measured with DIC.

The normal stresses, $\sigma_{R R}$ and $\sigma_{T T}$, were determined as the vertical force divided by the initial minimum cross-section; and the rolling shear stress, $\tau_{R T}$, was calculated as the horizontal force divided by the initial minimum cross-section in the center of the specimens. Corresponding cross-sectional areas amounted to $1000 \mathrm{~mm}^{2}$ for Q-shaped specimens, $800 \mathrm{~mm}^{2}$ for $\mathrm{V}$ - and T-shaped specimens, and $300 \mathrm{~mm}^{2}$ for D-shaped specimens.

The gradient from half of the first unloading path of the stress-strain curve, see Fig. 3, was considered when calculating the Young's moduli of elasticity in the radial and tangential directions, $E_{R}$ and $E_{T}$, and the rolling shear modulus, $G_{R T}$. The unloading path was chosen to determine the elastic material parameters, since elasticity is defined as the mechanically recoverable energy stored in the loaded sample (Bader et al. 2016).

To compare the test data with failure criteria, stress states at specific strain states were plotted in the $\sigma_{R R^{-}} \tau_{R T}$ and $\sigma_{T T}$ $-\tau_{R T}$ stress planes. Stress points were considered at $1 \%$ and $2 \%$ compressive strains. These stress points were chosen to study the onset and the development of plastic failure of the material. These stress points were then compared to previously suggested failure criteria discussed in Sect. 2. The predictions of failure criteria were calculated by using the uniaxial strength properties as determined in uniaxial tests. Uniaxial compressive strength was determined as the stress at $1 \%$ compressive strain, while the maximum stress was considered as strength in tensile and rolling shear tests. In the case of failure criteria that do not distinguish between

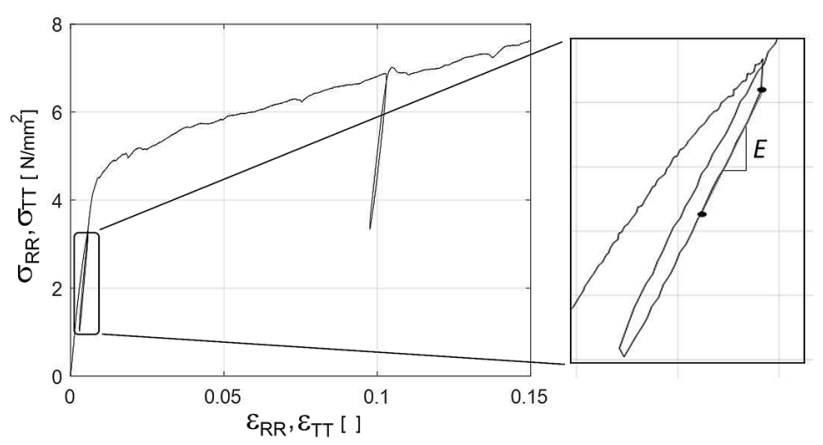

Fig. 3 Stress-strain relationship, loading sequences and calculation of modulus of elasticity and shear modulus from the first unloading path 
tensile and compressive strength, the compressive strength was considered for calculations. To assess the suitability of phenomenological failure criteria, the prediction capability, $R$ of these failure criteria were calculated instead of fitting the criteria. $R$-value equal to 1 means failure prediction is perfect. $R>1$ means the criterion underestimates and $R<1$ means the criterion overestimates the failure. $R$ is calculated from the experimental stress and material strength values.

The value $R$, for example in the case of quadratic criteria, can be calculated as

$\left(\frac{1}{R} \frac{\sigma_{R R}}{f_{R}}\right)^{2}+\left(\frac{1}{R} \frac{\sigma_{T T}}{f_{T}}\right)^{2}+\left(\frac{1}{R} \frac{\tau_{x y}}{f_{v, R T}}\right)^{2}=1$,

which for $\sigma_{T T}=0$ in the considered stress interaction gives

$R=\sqrt{\left(\frac{\sigma_{R R}}{f_{R}}\right)^{2}+\left(\frac{\tau_{x y}}{f_{v, R T}}\right)^{2}}$.

\section{Results and discussion}

\subsection{Test setup effects}

During the development of a suitable and efficient setup for biaxial testing in the R-T plane, test setup effects such as geometry and boundary or force imposing effects were studied. Loading was applied by means of two different devices, one with direct compression contact in L-shaped steel blocks and one with mechanical grips. Note that L-blocks restricted the horizontal (global x-direction) deformation of the test specimens in the corners, which led to shear stress even under pure compressive force. Moreover, compression tests were conducted with constrained horizontal displacement, which yielded a global shear force. The L-block setup developed a higher shear force than mechanical grips, which was particularly pronounced in biaxial loading. Mechanical grips, on the other side, allowed for deformation of the specimens in the horizontal direction, but led to stronger constraints in the load introduction area, where even deformation in the transverse (global z-direction) direction was constrained. Another important difference between the loading setup was that the mechanical grips reduced the unsupported height of the specimen.

Test specimens were tested in two different orientations, where either the radial or the tangential direction was parallel to the global y-direction, see Fig. 1. In radial compression, cell layers are compressed and the void volume is continuously reduced until the cells are fully compressed and the cell layer material is fully densified (MackenzieHelnwein et al. 2003). In tangential compression, however, buckling of the latewood cell layers is the predominant failure mechanism (Bodig 1965; Tabarsa 1999), and thus, the height of the specimen is of importance for the overall force carrying capacity. Due to these differences in the material response in the two orthogonal directions, setup effects were more pronounced for testing in the tangential direction than in the radial direction. This is clearly visible in Fig. 4a, which shows stress-strain relationships as determined by compression tests on Q-type specimen, using L-shaped (represented by solid lines) and gripped loading setup (represented by dashed lines). Differences in the initial behavior due to further deformation in the contact case compared to the mechanical gripping, become obvious, while the overall shape of the curves and the stress levels are rather similar. For compression testing in the tangential direction, however, considerable differences in the stress levels have been observed with higher stresses in the case of L-profiles, which is a consequence of boundary effects. This was obvious when comparing Q- and D-type specimens under tangential compression, as discussed in the next subsection. All tests except 'L-QR' tests were stopped at a strain level of about 0.30 .

Rolling shear tests were performed by either constraining displacement or force in the global vertical direction. The vertical force was restricted up to $100 \mathrm{~N}$ for Q-, V-, and $\mathrm{T}$-shaped specimens, and $50 \mathrm{~N}$ for $\mathrm{D}$-shaped specimens, and thus limited to nominal compressive stresses of $0.10 \mathrm{~N} / \mathrm{mm}^{2}$ for Q-shaped specimens and $0.17 \mathrm{~N} / \mathrm{mm}^{2}$ for D-shaped
Fig. 4 Stress-strain relationships from uniaxial compression testing of quadratic $(\mathrm{Q})$ and dog-bone shaped (D) test specimens, with different force imposing systems $(\mathrm{L} / \mathrm{G})$, in radial $(\mathrm{R})$ and tangential $(\mathrm{T})$ directions, for the assessment of a test setup effects, $\mathbf{b}$ geometry effects

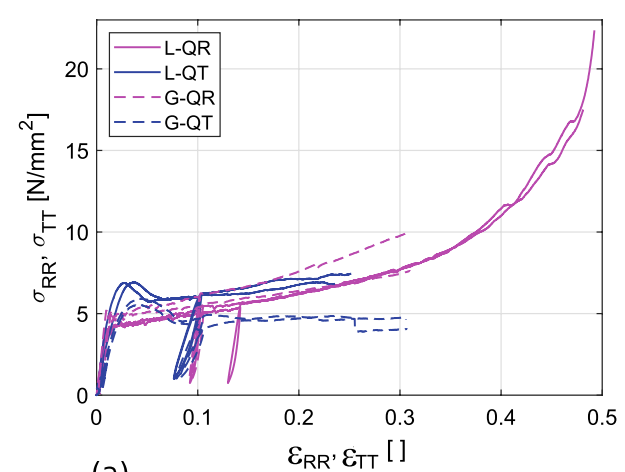

(a)

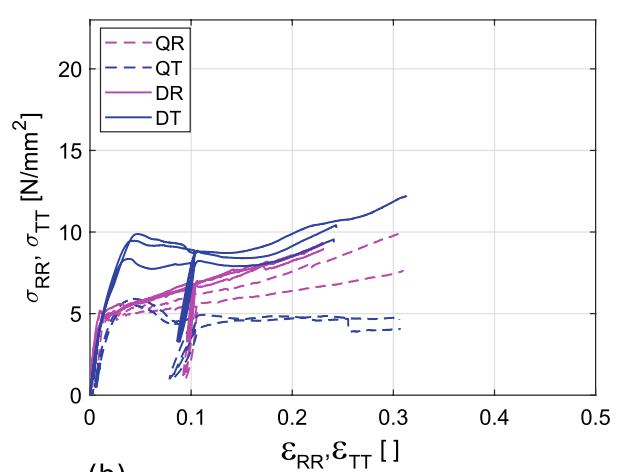

(b) 


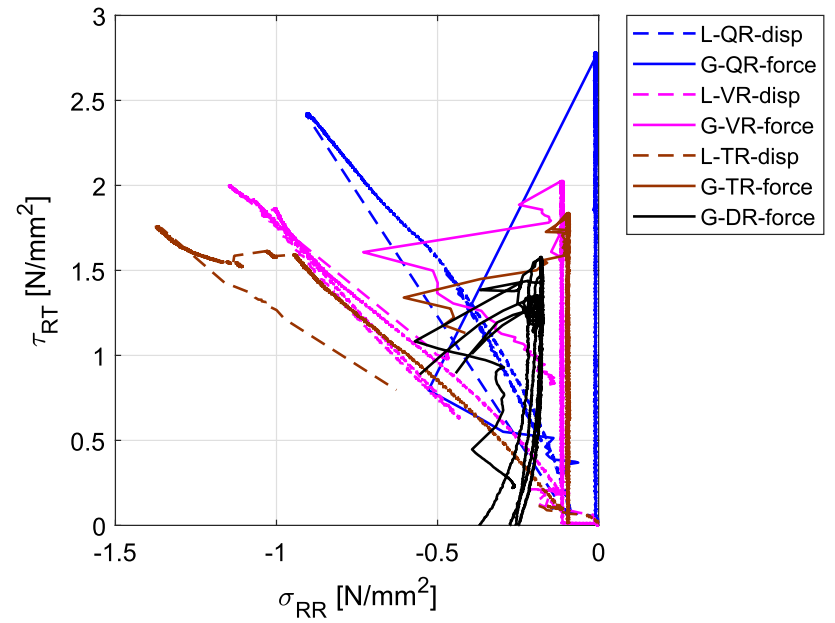

Fig. 5 Rolling shear stress vs. normal stress in shear testing of different specimens (Q-, V-, T- and D-shaped), with different force imposing systems $(\mathrm{L} / \mathrm{G})$ under force or displacement controlled boundary conditions in the lateral direction. Testing in radial (R) direction

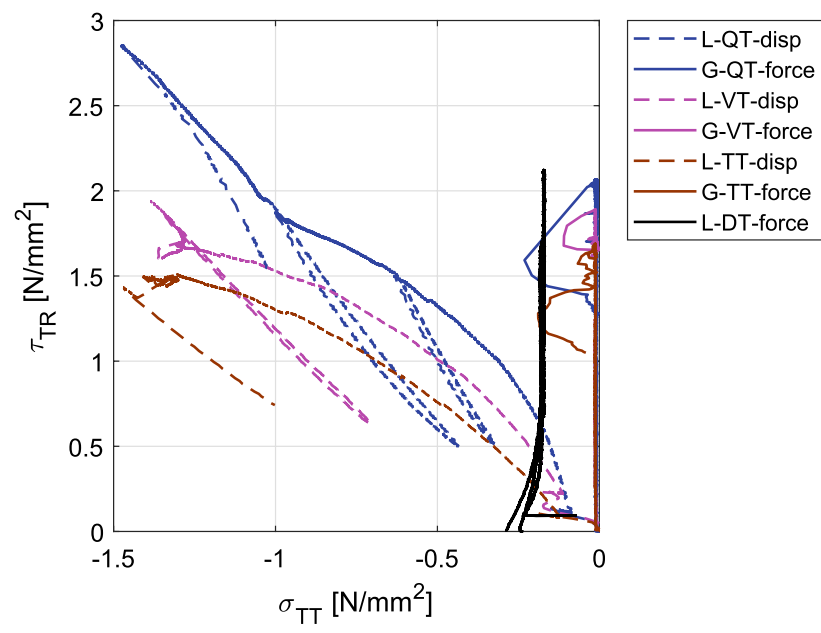

Fig. 6 Rolling shear stress vs. normal stress in shear testing of different specimens (Q-, V- and T- and D-shaped), with different force imposing systems (L/G) under force or displacement controlled boundary conditions in the lateral direction. Testing in tangential (T) direction

specimens. Therefore, not only could the effects of the force imposing system be assessed, but also the loading protocol.

Figures 5 and 6 show the stress paths of shear tests in the $\sigma_{R R^{-}} \tau_{R T}$ and $\sigma_{T T^{-}} \tau_{T R}$ stress planes. This indicates the two possible material orientations of specimens in shear testing, which both lead to shear stresses in the R-T plane. Force and displacement-constrained testing is indicated by force and disp. The figures illustrate the effects of the loading protocol and highlight the development of compressive stresses of more than $1 \mathrm{~N} / \mathrm{mm}^{2}$ in cases of displacement constrained testing, which partly lead to higher shear strength. Q-, V-, and T-shaped specimens were tested with direct contact and mechanical grips, while D-shaped specimens were tested with mechanical grips only. The effects of the force imposing system on shear strength seem to be insignificant or overlaid by variation of the shear strength.

In the case of biaxial loading, direct contact through the L-blocks led to complex surface strain distributions, such as tensile stress in the two opposite sides of the L-plates with stress concentration near the notch, and thus cracks developed undesired failure modes. Moreover, differences in the stress paths were observed for the same displacement loading path. Mechanical grips yielded comparably lower shear stress, whereas force imposed by contact led to higher nominal shear stress but lower nominal normal stress. This effect was pronounced for compression in the radial direction. However, the post-elastic behavior of the material was similar for the two test setups. Hardening in biaxial testing with the radial compression led to strongly increased rolling shear stresses, while biaxial testing with tangential compression led to considerably increased compression stresses and rolling shear stress softening.

The assessment showed that mechanical grips led to a more homogeneous force transmission and avoided stress concentrations that occurred in the corners of the L-shaped contact device. The influences of the specimen's shape combined with the force imposing system on the stress state in the specimens and on mechanical properties derived from testing are assessed next.

\subsection{Geometry effects}

A balance in the shape and size of the specimens for biaxial testing is obviously required because shear testing would require flat specimens to reduce the eccentricity in the shear loading, whereas compression testing would require higher specimens to avoid any boundary effects. The influence of specimen shape on the shear behavior was mentioned in the previous section, where the unsupported height of the specimen was found to affect the mechanical response when testing in the tangential direction. The height of the specimens greatly influenced the development of higher nominal stress in compressive testing as well. This is illustrated in Fig. 4b. A reason for the difference is that the nominal compressive stress was calculated using the minimum cross-sectional area. For tangential testing, however, the material above and below the reduced cross-section contributes to the force distribution, as seen in the strain fields, which will be discussed later. Another possible reason is that the average density of the T-specimens is higher than the density of the R-specimens, which can yield higher compressive stress. No compression tests were carried out on $\mathrm{V}$ and $\mathrm{T}$-shaped specimens. Therefore, no comparison is shown for these two types of specimens. 
The effect of the specimen's shape was also included in Figs. 5 and 6, where there were no considerable differences for rolling shear testing. The stress state under shear testing was more closely assessed by means of rolling shear strain distributions across the specimens, as measured by digital image correlation. As with stress plane figures, strain sections are evaluated for specimens tested in the two material orientations, RT and TR. The strain sections in Figs. 7 and 8 clearly show the influence of the annual ring structure, since a more homogeneous strain level was found for R-oriented specimens, while alternating shear strain levels were visible in T-oriented specimens. Figures 7 and 8 also show the differences between specimen shapes as well as some variation when testing similar specimens but with different loading protocols. Shear strains were taken at a nominal shear stress level of $1 \mathrm{~N} / \mathrm{mm}^{2}$. Note that all shear tests with force constrained loading were accomplished by using mechanical grips. D-shaped specimens showed the least strain concentrations in the area of interest and least edge concentrations, compared to other shapes.

Rolling shear strain-stress relationships for D-shaped specimens are shown in Fig. 9 for RT- (R) and TR- (T) orientations. When the shear plane is parallel to the radially stacked annual rings, RT-orientation led to an almost perfect brittle failure, whereas when the shear plane crosses several annual rings, TR-orientation testing led to a more progressive brittle failure through the development of several cracks. The latter failure mechanisms occurred at comparably higher stress levels. However, as a consequence of the homogeneous orthotropic material, no difference was considered between rolling shear strength in RT- and TRorientation compared to failure criteria.

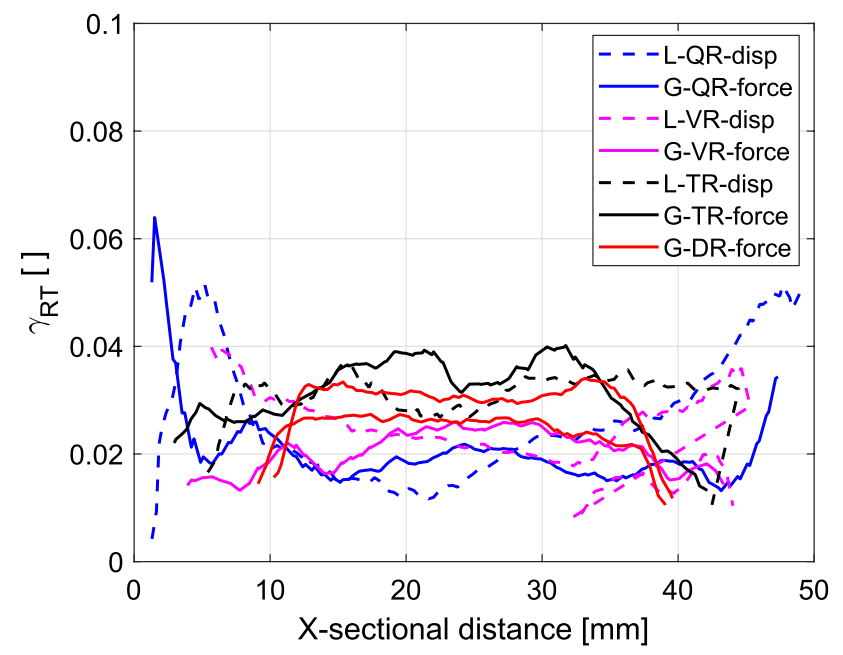

Fig. 7 Rolling shear strain along mid-section in radial (R) orientation shear testing of different specimens (Q-, V-, T- and D-shaped), with different force imposing systems $(\mathrm{L} / \mathrm{G})$ under force or displacement controlled boundary conditions

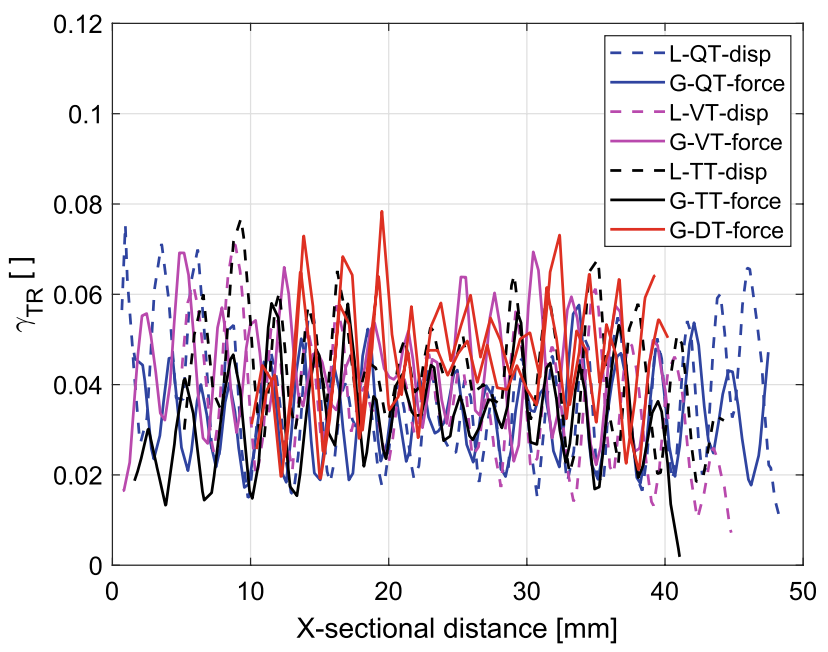

Fig. 8 Rolling shear strain along mid-section in tangential (T) orientation shear testing of different specimens (Q-, V-, T- and D-shaped), with different force imposing systems (L/G) under force or displacement controlled boundary conditions

The strain field under biaxial testing is assessed next for SC-45 testing. Figure 10 shows the normal strain and shear strain fields for all investigated specimen shapes and testing in the two orthogonal directions $\mathrm{R}$ and $\mathrm{T}$. Strain fields represent the state at a nominal compressive stress of $3 \mathrm{~N} / \mathrm{mm}^{2}$ and corresponding shear stresses between 0.11 and 1.48 $\mathrm{N} / \mathrm{mm}^{2}$. Because D-shaped specimens were tested with mechanical grips and all other shapes with L-shape steel plates, considerably lower shear stresses developed in the D-shaped specimens. The DIC assessment revealed comparatively uniform surface strain distributions for all geometries, except for some stress concentration at the edges.

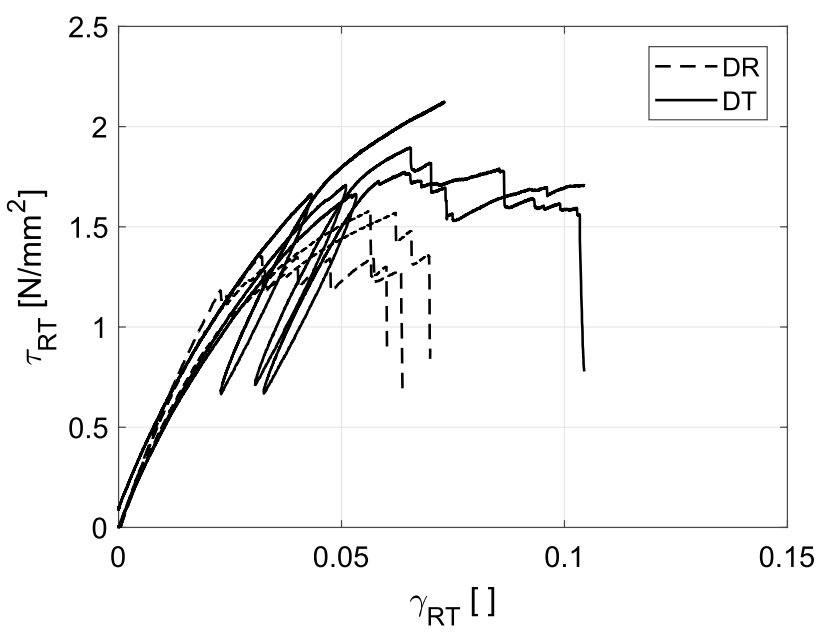

Fig. 9 Rolling shear stress $\left(\tau_{R T}\right)$ vs. rolling shear strain $\left(\gamma_{R T}\right)$ in shear testing on dog-bone shaped (D) specimens in the radial (R) and tangential $(\mathrm{T})$ material orientations 


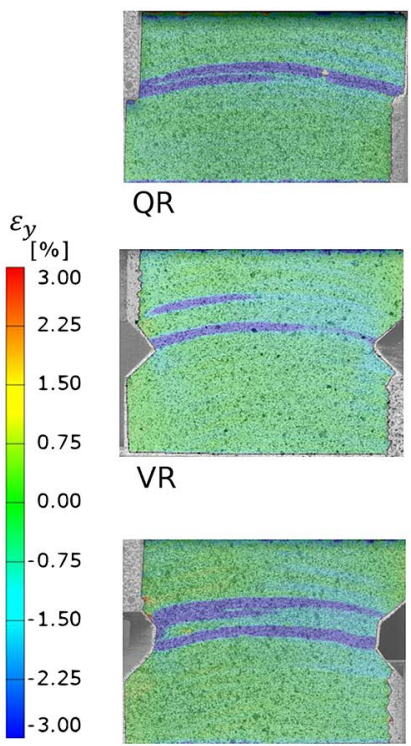

TR

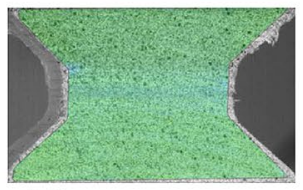

DR
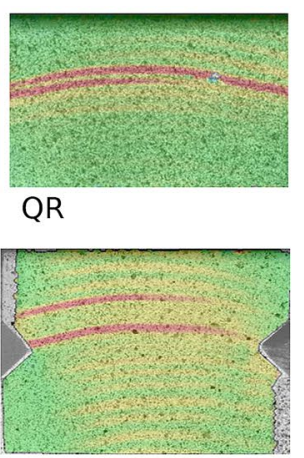

VR

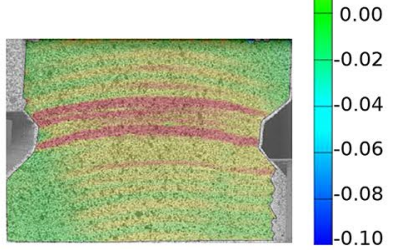

TR

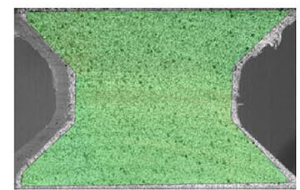

DR

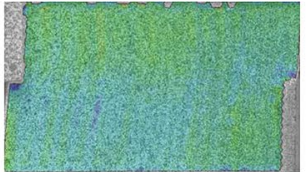

$$
\text { QT }
$$

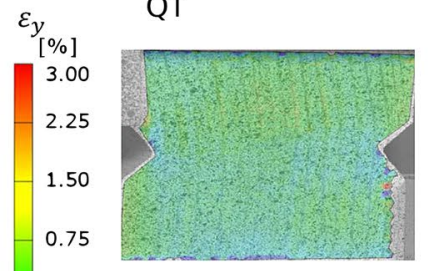

VT

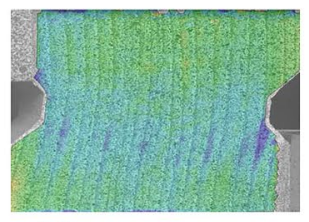

Tा

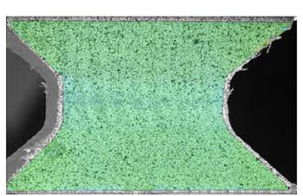

DT
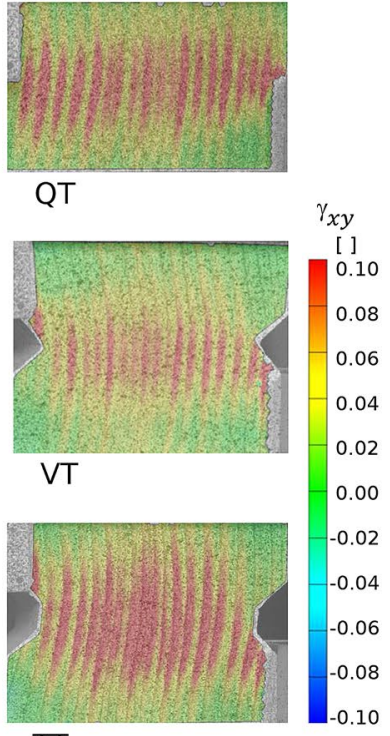

TT

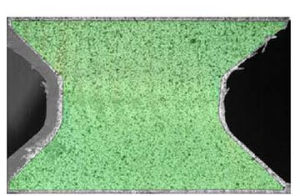

DT

Fig. 10 Compressive strain $\left(\varepsilon_{y}\right)$ and rolling shear strain $\left(\gamma_{x y}\right)$ fields under SC-45, biaxial testing of different specimens (Q-, V-, T- and D-shaped)

The reduced cross-section in the notched area in V-, T-, and D-shaped specimens helped to yield a concentrated strain distribution and initiate a crack in this part. However, this was not always achieved in Q-type specimens of biaxial testing with compression in the radial direction. Biaxial testing with compression in the tangential direction highlighted the

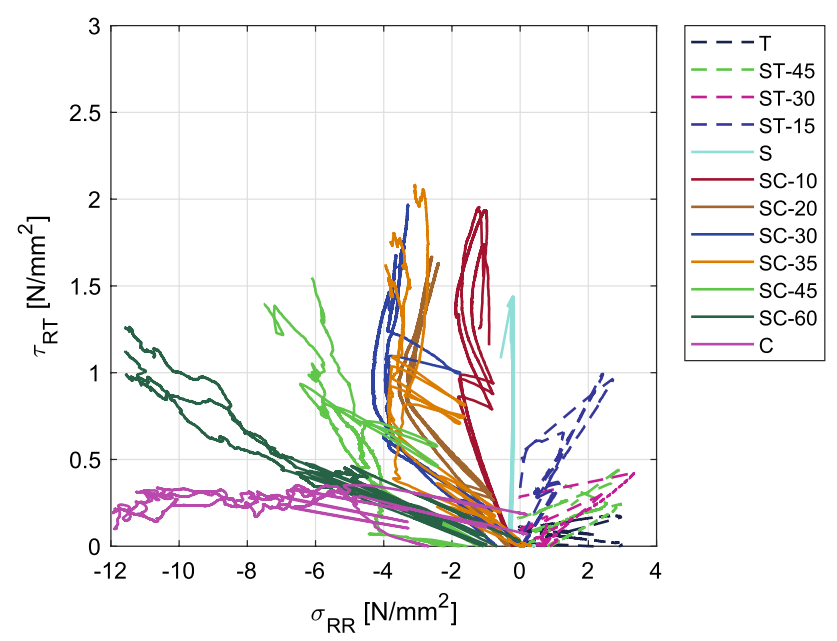

Fig. 11 Stress paths for displacement controlled testing in the rolling shear stress vs. normal stress plane for DR test series sample shape effect on the tangential strain-stress response. The nominal tangential compressive stress increased with the increased notch size. Activation of the material above and below the notched area is well visible in the corresponding shear strain fields.

Finally, the material properties derived from nominal strain-stress relationships measured on different specimen shapes are compared. The Young's moduli in the radial and the tangential directions, and the rolling shear moduli were calculated from unloading paths as described in Sect. 3.3, which yielded values shown in Table 1. For testing under radial compression, minor differences were observed for the different types of specimens and force imposing devices, as well as when comparing tensile and compressive stiffness. The corresponding strengths between 4 and $5 \mathrm{~N} / \mathrm{mm}^{2}$ were measured. A slightly higher variation was found for testing under tangential compression. The rolling shear stiffness and strength, however, showed higher variations for different shapes of specimens, and thus, different stressed volume. As a consequence, Q-type specimens yielded higher rolling shear stiffness and strength than V-, T-, and D-type specimens. The high influence of stressed volume on shear strength was mentioned by Steiger and Gehri (2011). The rolling shear modulus was between 50 and $60 \mathrm{~N} / \mathrm{mm}^{2}$ for almost all setups and specimen shapes with notches. This 


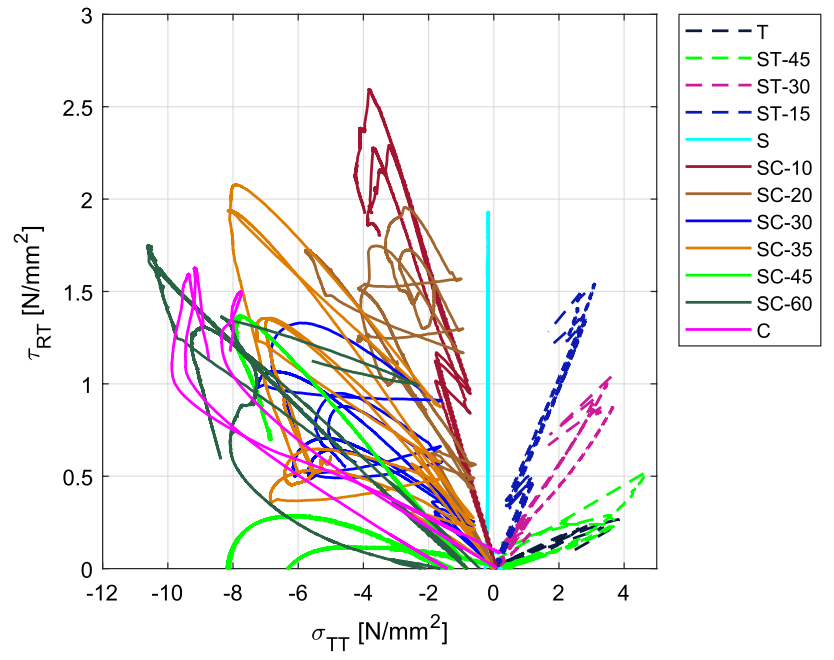

Fig. 12 Stress paths for displacement controlled testing in the rolling shear stress vs. normal stress plane for DT test series

corresponds well with values given in previous scientific works (e.g. Dumail et al. 2000; Hassel et al. 2009 and material standard EN 338 2009). Dog-bone shaped specimens exhibited the lowest rolling shear strength value, which is expected as a consequence of the reduced cross-section and less effect of the curvature of the annual ring structure. The highest rolling shear stiffness and strength were found for Q-type specimens, which showed some curvature of the annual ring structure, even if the test specimens were cut from the outermost part of the tree. The influence of the sawing pattern on the rolling shear modulus is well-known in wood science, see for example Aicher and Dill-Langer (2000). Because dog-bone shaped specimens have been further used for biaxial testing, the following average material properties have been considered for the assessment of biaxial failure criteria.

- Modulus of elasticity in radial direction, $E_{R}=830 \mathrm{~N} / \mathrm{mm}^{2}$,

- Modulus of elasticity in tangential direction, $E_{T}=545 \mathrm{~N} / \mathrm{mm}^{2}$,

- Rolling shear modulus in R-T plane, $G_{R T}=55 \mathrm{~N} / \mathrm{mm}^{2}$,

- Compressive strength in radial direction, $f_{c, R}=4.58 \mathrm{~N} / \mathrm{mm}^{2}$,

- Tensile strength in radial direction, $f_{t, R}=2.75 \mathrm{~N} / \mathrm{mm}^{2}$,

- Tensile strength in tangential direction, $f_{t, T}=3.28 \mathrm{~N} / \mathrm{mm}^{2}$,

- Rolling shear strength R-T plane, $f_{v, R T}=1.54 \mathrm{~N} / \mathrm{mm}^{2}$.

Uni-axial compression and rolling shear testing of dogbone shaped specimens resulted in typical material behavior. The radial compression tests yielded linear elastic behavior, followed by a stress plateau with slightly increasing stress (Bodig 1963; Tabarsa 1999). However, tangential compression resulted in a non-linear behavior and a stress peak, a consequence of latewood layer buckling (Tabarsa 1999). Modulus of elasticity in the radial direction was higher than in the tangential direction, and agrees well with previous findings (e.g. Madsen et al. 1982; Hall 1980; Gehri 1997; Farruggia and Perré 2000; Hoffmeyer et al. 2000; Kristian 2009; Zhong et al. 2015). $E_{R}$ was 1.50 times higher than $E_{T}$, which is in agreement with Zhong et al. (2015), but comparatively lower than the findings of Gehri (1997), Farruggia and Perré (2000), Hoffmeyer et al. (2000) and Kristian (2009), who reported a factor of around 2 .

The compressive strength in the radial direction that was determined higher than in the tangential direction is in agreement with Gehri (1997), Hall (1980) and Hoffmeyer et al. (2000). However, when considering the stress peak in the tangential direction, $f_{c, T}$ was found to be higher than $f_{c, R}$, see Table 1. Since the value in the tangential direction was dependent on specimen shape and height, it may not reflect the real material strength. It is emphasized that Table 1 only summarizes uniaxial tests for compression and tension perpendicular to the grain as well as rolling shear, where a total of 38 tests were performed.

The tensile strength in the tangential direction was higher than in the radial direction, with values of $f_{t, T}=3.28 \mathrm{~N} / \mathrm{mm}^{2}$ and $f_{t, R}=2.75 \mathrm{~N} / \mathrm{mm}^{2}$, which is in contradiction to Kristian (2009), who reported $f_{t, R}=4.90 \mathrm{~N} / \mathrm{mm}^{2}$ and $f_{t, T}=2.80 \mathrm{~N} / \mathrm{mm}^{2}$. By considering the brittle behavior under tensile loading, tests on a higher number of specimens could give better insight into tensile strength.

The determined rolling shear modulus of $G_{R T}=55 \mathrm{~N} / \mathrm{mm}^{2}$ is in good agreement with findings by Dumail et al. (2000) and Hassel et al. (2009), while the rolling shear strength, $f_{v, R T}=1.54 \mathrm{~N} / \mathrm{mm}^{2}$, is slightly lower than the value of 1.60 $\mathrm{N} / \mathrm{mm}^{2}$ reported by Kristian (2009), Dumail et al. (2000) and Hassel et al. (2009).

\subsection{Biaxial testing and assessment of failure criteria}

Biaxial testing of dog-bone shaped specimens was performed along 12 displacement paths, including combinations of rolling shear with compression and tension perpendicular to the grain. The corresponding stress paths are shown for normal stresses in the radial (Fig. 11) and tangential (Fig. 12) material directions. Note that the datasets shown in Figs. 11 and 12 consist of 36 tests each for DR and DT specimens, i.e., a total of 72 tests, performed on DR and DT specimens. Brittle failure was observed for the combination of tensile stresses with rolling shear, while ductile behavior was observed for the combination of compressive stresses with rolling shear. A transition zone from brittle failure under pure rolling shear to a ductile behavior in combination with compressive stresses was found for displacement paths SC-10 and SC-20. By comparing stress interaction paths in the radial and tangential directions, it 
Table 1 Influence of geometry and setup effects on material properties derived from nominal strain-stress relationships

\begin{tabular}{|c|c|c|c|c|}
\hline $\begin{array}{l}\text { Setup and } \\
\text { specimen }\end{array}$ & Test type & Tests $n$ & $\begin{array}{l}\text { Stiffness } \\
\left(\mathrm{N} / \mathrm{mm}^{2}\right)\end{array}$ & $\begin{array}{l}\text { Strength } \\
\left(\mathrm{N} / \mathrm{mm}^{2}\right)\end{array}$ \\
\hline L-QR & Compression & 2 & $E_{R}=810$ & $f_{c, R}=3.81$ \\
\hline G-QR & Compression & 2 & $E_{R}=880$ & $f_{c, R}=5.03$ \\
\hline G-DR & Compression & 3 & $E_{R}=830$ & $f_{c, R}=4.58$ \\
\hline G-DR & Tension & 2 & $E_{R}=828$ & $f_{t, R}=2.76$ \\
\hline L-QT & Compression & 2 & $E_{T}=655$ & $\begin{array}{c}f_{c, T}=3.13 \\
\left(6.92^{\mathrm{a}}\right)\end{array}$ \\
\hline G-QT & Compression & 2 & $E_{T}=460$ & $\begin{array}{l}f_{c, T}=2.51 \\
\quad\left(5.72^{\mathrm{a}}\right)\end{array}$ \\
\hline G-DT & Compression & 3 & $E_{T}=546$ & $\begin{array}{c}f_{c, T}=4.26 \\
\left(9.23^{\mathrm{a}}\right)\end{array}$ \\
\hline G-DT & Tension & 3 & $E_{T}=542$ & $f_{t, T}=3.28$ \\
\hline L-QR & Rolling shear & 1 & $G_{R T}=126$ & $f_{v, R T}=2.42$ \\
\hline G-QR & Rolling shear & 1 & $G_{R T}=143$ & $f_{v, R T}=2.78$ \\
\hline L-QT & Rolling shear & 1 & $G_{T R}=107$ & $f_{v, R T}=2.85$ \\
\hline G-QT & Rolling shear & 1 & $G_{T R}=114$ & $f_{v, R T}=2.07$ \\
\hline L-VR & Rolling shear & 1 & $G_{R T}=54$ & $f_{v, R T}=2.00$ \\
\hline G-VR & Rolling shear & 1 & $G_{R T}=60$ & $f_{v, R T}=2.02$ \\
\hline L-VT & Rolling shear & 1 & $G_{T R}=54$ & $f_{v, R T}=2.00$ \\
\hline G-VT & Rolling shear & 1 & $G_{T R}=60$ & $f_{v, R T}=1.89$ \\
\hline L-TR & Rolling shear & 1 & $G_{R T}=33$ & $f_{v, R T}=1.76$ \\
\hline G-TR & Rolling shear & 1 & $G_{R T}=50$ & $f_{v, R T}=1.84$ \\
\hline L-TT & Rolling shear & 1 & $G_{T R}=58$ & $f_{v, R T}=1.5$ \\
\hline G-TT & Rolling shear & 1 & $G_{T R}=58$ & $f_{v, R T}=1.69$ \\
\hline G-DR & Rolling shear & 4 & $\begin{array}{l}G_{R T}=54 \text { (load- } \\
\quad \text { ing) }\end{array}$ & $f_{v, R T}=1.38$ \\
\hline G-DT & Rolling shear & 3 & $G_{T R}=55$ & $f_{v, R T}=1.76$ \\
\hline
\end{tabular}

${ }^{\mathrm{a}}$ Maximum stress

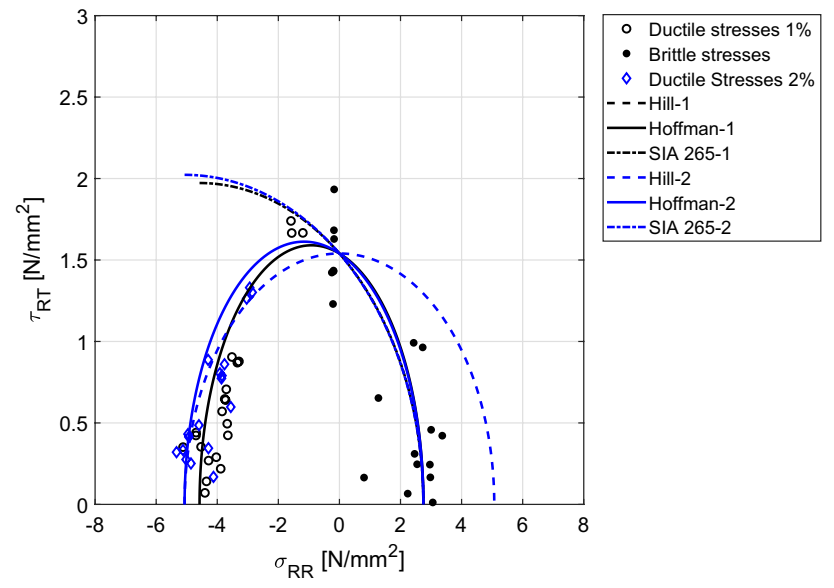

Fig. 13 Comparison of failure criteria with experimental data, considering compressive strength at $1 \%$ and $2 \%$ compressive strain level for DR test series

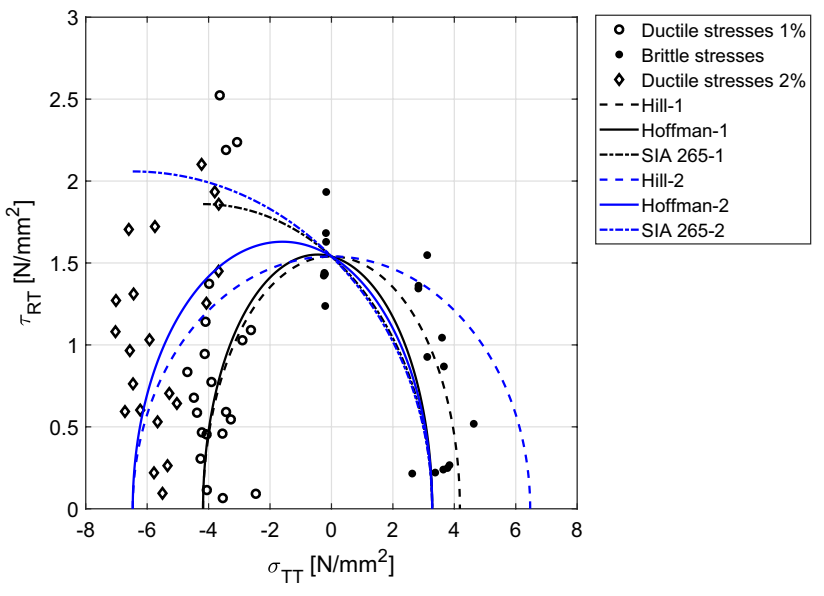

Fig. 14 Comparison of failure criteria with experimental data, considering compressive strength at $1 \%$ and $2 \%$ compressive strain level for DT test series

is interesting that comparably higher shear stresses were observed for tangential compression than for radial compression, which means a stiffer shear behavior for this combination. This is a consequence of the displacement controlled testing and the ratio between Young's modulus and rolling shear stiffness that is lower in the tangential direction; cf. stiffness properties given in Sect. 4.2.

Another interesting observation was the different postelastic behavior of clear wood in the two orthogonal orientations. When combined with radial compressive stresses, rolling shear stresses increased more than compressive stresses after the elastic limit was reached, see SC-45, SC-35, SC-30, SC-20 in Fig. 11. However, when combined with tangential compressive stresses, rolling shear stresses decreased after the elastic limit, see SC-45, SC-35, SC-30, SC-20 in Fig. 12.

Material strength properties were derived to assess the suitability of failure criteria. The strength was simply set equal to the maximum stress in case of brittle material failure under tension, shear and tension-shear stress combinations. For ductile failure in compression and shear-compression interaction, stress points at $1 \%$, and $2 \%$ compressive strains were evaluated instead. This is a typical procedure that is also specified in the material testing standard (EN 408 2010), which prescribes certain levels of permanent strain, though absolute strain was used here.

Material strength properties for strain levels of $1 \%$ and 2\% compressive strain were then compared to failure envelopes predicted by Hill, Hoffman and the SIA 265 design equation, see Figs. 13 and 14. Rolling shear strength and tensile strength were kept constant for the two strain states, whereas compressive strength levels were changed to follow the evolution of failure surfaces. In Figs. 13 and 14, Hill-1, Hoffman-1, SIA 265-1 curves denote the failure surfaces by Hill, 
Hoffman and SIA 265 design equation by considering compressive strength at $1 \%$ compressive strain level, whereas Hill-2, Hoffman-2, SIA 265-2 curves denote the failure surfaces by Hill, Hoffman, and SIA 265 design equation by considering compressive strength at $2 \%$ compressive strain level. However, because compressive strength changes, the failure envelope changes slightly in the tension-shear interaction state. For the Hill failure criterion, the compressive strength was used as the strength perpendicular to the grain. A stronger difference in the compression-shear interaction area was observed, due to increased stresses at higher strain levels. The suitability of the failure criteria is assessed by the prediction capability value $R$, given in Table 2 .

From the mean $R$-values in Table 2, none of the failure criteria yielded good prediction in both tension and compression interaction states in both material orientations. Overall, Hoffman's criterion shows better prediction in DRspecimens than in DT-specimens. When considering both stress states, the average $R$-value for Hoffman's criterion was found to be 0.95 , in comparison to Hill's criterion, which yielded a $R$-value of 0.85 for $1 \%$ compressive strain. Yet, in the DT-series, Hill's criterion yielded better prediction than Hoffman when considering both stress states (compressive and tensile), while Hoffman was found better in compressive stress states. However, both criteria showed a small difference in compressive stress states, since the shape of the failure envelope is very similar. The difference in tensile stress states is high, which is a reason to set the tensile strength equal to the compressive strength for non-consideration of material tensile strength by Hill's criterion. The latter was chosen here to assess the prediction quality of Hill's criterion in compressive stress states. It could then possibly be combined with a brittle failure criterion for tensile stress states.

The experimental data given in Figs. 11 and 14 shows that the combination of rolling shear with compressive forces perpendicular to the grain influences the strength positively (Steiger and Gehri 2011; SIA 265 2012) in failure up to a certain compressive stress level. The positive effect of compressive stress on rolling shear strength was confirmed by Mestek (2011) as well. Regarding the assessment of failure criteria, both Hill and Hoffman's criteria underestimate the positive effect of shear loading. Comparatively, Hoffman's criterion yielded a closer limit curve than Hill's criterion. This is a consequence of the possibility to account for different tensile and compressive strengths and the corresponding shift of the elliptical curve. The SIA 265 design equation gives, however, a good prediction for this transition zone. It would require a combination with a failure criterion for the compressive failure of wood in the radial or tangential direction, and thus, a multi-surface failure criterion.

\subsection{Failure mechanism in biaxial testing of dog-bone shaped specimens}

The failure patterns observed in the experiments are shown in Fig. 15. Radial compressive stress yielded ductile behavior with strength hardening, where wooden cells were progressively compressed and the material densified, leading to an increase in stress. Rolling shear, tensile, and combined tensile force with rolling shear in specimens tested in the $\mathrm{R}$-orientation led to brittle failure modes. A cascading type of brittle failure occurred under pure shear in this case, since cracking neither produced a smooth failure surface, nor followed that same annual ring. However, the radial tensile force and combined tensile force with rolling shear led to pure brittle failure with straight and smooth surfaces. Under combined compressive force with rolling shear, mixed failure modes, i.e., in between ductile and brittle failure modes, occurred, depending on the stress path (displacement ratios of normal stress to shear stress).

Tangential compressive stress led to buckling of the cells, causing damage to earlywood cells. A similar behavior was observed under biaxial stresses of combined compressive stress with rolling shear. Tensile, rolling shear, and combined tensile with rolling shear stress in this testing orientation yielded brittle failure. An almost straight crack was
Table 2 Assessment of failure criteria by comparison with experimental data; mean and standard deviation of prediction quality ratio, $R$

\begin{tabular}{|c|c|c|c|c|c|c|c|c|}
\hline \multirow[t]{2}{*}{ Specimen } & \multirow[t]{2}{*}{ Failure criteria } & \multicolumn{2}{|l|}{ Whole } & \multicolumn{2}{|c|}{ Compression } & \multicolumn{2}{|c|}{ Tension } & \multirow{2}{*}{$\begin{array}{l}\text { Failure } \\
\text { correspond } \\
(\%)\end{array}$} \\
\hline & & Mean & St. dev & Mean & St. dev & Mean & St. dev & \\
\hline \multirow[t]{4}{*}{ DR } & Hill, Eq. (8) & 0.85 & 0.20 & 0.98 & 0.09 & 0.70 & 0.19 & 1 \\
\hline & Hoffman, Eq. (13) & 0.95 & 0.15 & 0.94 & 0.10 & 0.95 & 0.19 & 1 \\
\hline & Hill, Eq. (8) & 0.82 & 0.21 & 0.93 & 0.11 & 0.70 & 0.19 & 2 \\
\hline & Hoffman, Eq. (13) & 0.90 & 0.18 & 0.86 & 0.16 & 0.95 & 0.19 & 2 \\
\hline \multirow[t]{4}{*}{ DT } & Hill, Eq. (8) & 1.08 & 0.25 & 1.19 & 0.29 & 1.02 & 0.16 & 1 \\
\hline & Hoffman, Eq. (13) & 1.13 & 0.25 & 1.10 & 0.30 & 1.17 & 0.14 & 1 \\
\hline & Hill, Eq. (8) & 1.02 & 0.27 & 1.15 & 0.21 & 0.83 & 0.24 & 2 \\
\hline & Hoffman, Eq. (13) & 1.13 & 0.20 & 1.10 & 0.24 & 1.16 & 0.13 & 2 \\
\hline
\end{tabular}




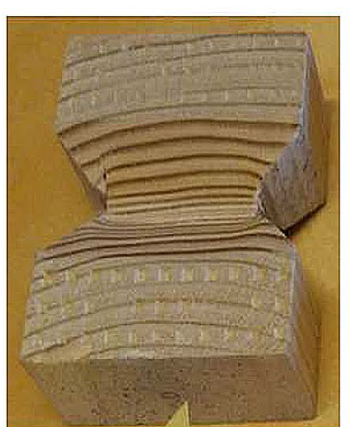

C

(a)

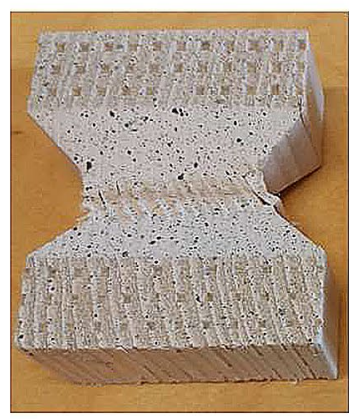

C

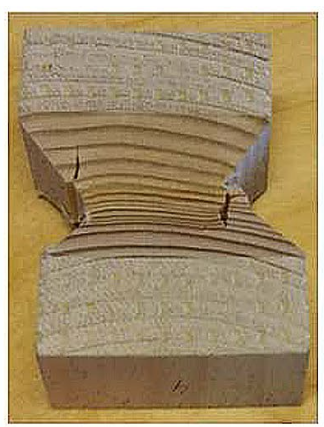

SC-45

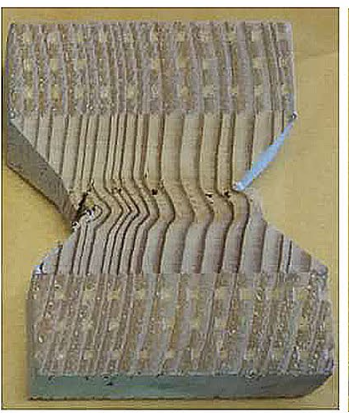

SC-60

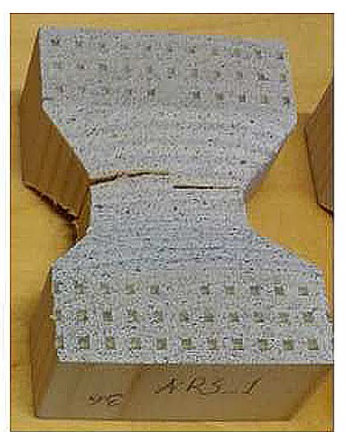

S

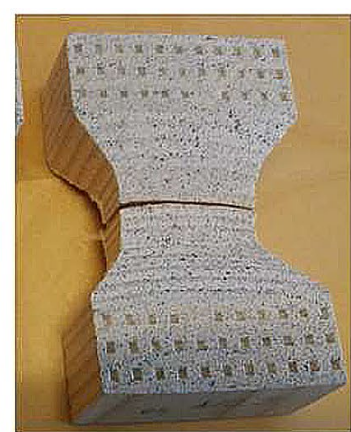

T

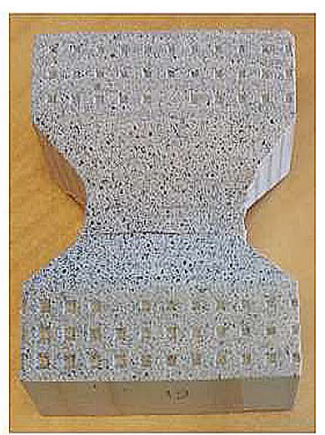

ST-15

(b)

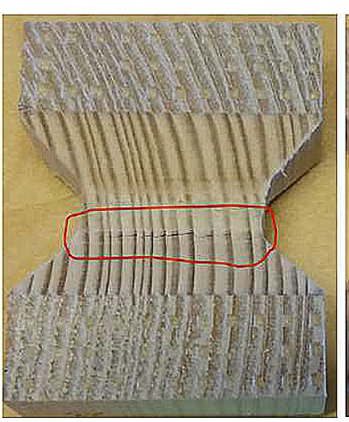

T

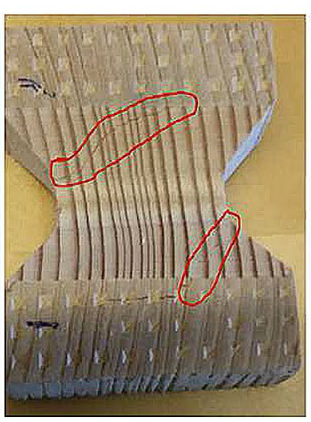

S

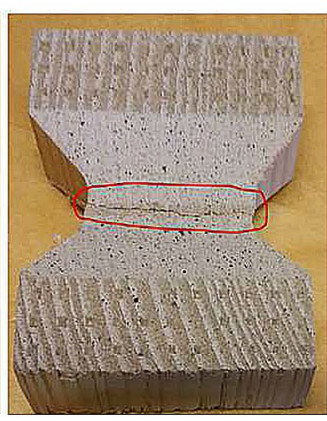

ST-45

Fig. 15 Failure modes: ductile behavior/failure under compression and combined compression with rolling shear, progressive brittle failure under rolling shear, and pure brittle failure under tension and combined tension with rolling shear in a DR-specimens and b DT-specimens

noticed for tangential tensile and combined tensile with rolling shear loading. Contrarily, failure started close to the notched area but extended at $45^{\circ}$ for rolling shear for testing with tangential orientation.

\section{Conclusion}

A test setup to study the mechanical behavior of clear wood, under a combination of normal stresses perpendicular to the grain with rolling shear stress was developed. This was challenging due to the requirements of generating pure rolling shear, compressive, and tensile stress states as well as combined stress states in one experimental setup. The determined strain fields from experiments with a DIC system confirmed rather uniform and homogeneous strain development, and suitable failure modes were observed with the biaxial test setup. An investigation of the force imposing setup and specimen shape effects demonstrated the need for a continuous force transfer and force distribution effects in the specimen, which were most pronounced for testing in the tangential direction. Dog-bone shaped specimens were chosen to assess the biaxial failure criteria since the volume of interest and the failure region are well-defined.

Differences in material behavior in the radial and tangential directions were observed in the experimental study. Modulus of elasticity was found higher in the radial direction than in the tangential direction. Minor differences were even observed for the two orientations in rolling shear testing. Uniaxial material properties and strength, in tension, compression, and shear were in good agreement with previous studies.

Testing along 12 displacement paths with different ratios of tensile/compressive and shear displacements, covered the stress space in the transverse plane of wood well. A small transition zone from brittle failure in tension and shear to ductile failure in shear-compression combinations was observed. Moreover, the combination of rolling shear stress with compressive stress led to an increase in the rolling shear strength, before the shear strength was reduced at higher compressive stress levels. This phenomenon is also observed in combination with longitudinal shear stresses in wood. 
Finally, the experimental data was compared with Hill's and Hoffman's failure criteria and the SIA 265 design equation for longitudinal shear interaction with stresses perpendicular to the grain. Overall, Hoffman's failure criterion yielded the highest prediction quality with experimentally evaluated failure stresses, in specimens with radial compression. For tangential compression, however, Hill's failure criterion gave less error than Hoffman's criterion, due to higher variation in experimental results. A positive effect on rolling shear with compression perpendicular to the grain was observed in experiments, though it was not well predicted by Hill's or Hoffman's failure criteria. The SIA 265 design equation is better suited for this phenomenon in the transition from shear to compression. Thus, a more complex mathematical function or a combination of criteria in a so-called multi-surface failure criterion would be better suited to include the positive influence of rolling shear in the failure of wood for such stress interaction.

The findings of the experimental campaign demonstrate the challenge in determining material properties, which obviously are often rather system properties than material characteristics. Therefore, the combination of the experimental data with numerical modeling for the development of a material model that suitably represents the elasto-plastic macroscopic material behavior would give further insight into the suitability of the test setup. Corresponding numerical models of specimens in the test setup have been developed and the results will be presented in another article. The potential of the test setup can be utilized to build a sound database for engineering design and future model validation by investigating the material behavior at other moisture contents relevant for engineering applications and testing of further wood species.

Acknowledgements Open access funding provided by Linnaeus University. This research work was funded by the Swedish research council FORMAS through the project 'Compression perpendicular to the grain in cross-laminated engineered wood-based products' (2016-01086).

\section{Compliance with ethical standards}

Conflict of interest The authors declare that they have no conflict of interest.

Open Access This article is licensed under a Creative Commons Attribution 4.0 International License, which permits use, sharing, adaptation, distribution and reproduction in any medium or format, as long as you give appropriate credit to the original author(s) and the source, provide a link to the Creative Commons licence, and indicate if changes were made. The images or other third party material in this article are included in the article's Creative Commons licence, unless indicated otherwise in a credit line to the material. If material is not included in the article's Creative Commons licence and your intended use is not permitted by statutory regulation or exceeds the permitted use, you will need to obtain permission directly from the copyright holder. To view a copy of this licence, visit http://creativecommons.org/licenses/by/4.0/.

\section{References}

Aicher S, Dill-Langer G (2000) Basic considerations to rolling shear modulus in wooden boards. Otto-Graf J 11:157-166

Aicher S, Klöck W (2001) Linear versus quadratic failure criteria for inplane loaded wood based panels. Otto-Graf J 12:187

Arcan M, Hashin Z, Voloshin A (1978) A method to produce uniform plane-stress states with applications to fiber-reinforced materials. Exp Mech 18(4):141-146

Azzi V, Tsai S (1965) Anisotropic strength of composites. Exp Mech 5(9):283-288

Bader TK, Dastoorian F, Ebrahimi G, Unger G, Lahayne O, Hellmich C, Pichler B (2016) Combined ultrasonic-mechanical characterization of orthotropic elastic properties of an unrefined bagasse fiber-polypropylene composite. Compos Part B Eng 95:96-104

Blass H, Görlacher R (2004) Compression perpendicular to the grain. In: Proc. 8th world conference on timber engineering (WCTE), vol 2, WCTE, Lahti, pp 435-440

Bleron L, Denaud L, Collet R, Marchal R (2011) Experimental study of locally loaded timber in compression perpendicular to the grain. Eur J Environ Civil Eng 15(3):357-366

Bodig J (1963) A study of the mechanical behavior of wood in transverse compression. University of Washington, Seattle

Bodig J (1965) The effect of anatomy on the initial stress-strain relationship in transverse compression. For Prod J 15:197-202

Cabrero J, Blanco C, Gebremedhin K, Martin-Meizoso A (2012) Assessment of phenomenological failure criteria for wood. Eur J Wood Prod 70(6):871-882

Dumail J, Olofsson K, Salmén L (2000) An analysis of rolling shear of spruce wood by the Iosipescu method. Holzforschung 54(4):420-426

Eberhardsteiner J (2013) Mechanisches Verhalten von Fichtenholz: Experimentelle Bestimmung der biaxialen Festigkeitseigenschaften (Mechanical behaviour of spruce; experimental determination of biaxial strength properties). Springer, Berlin (in German)

Ehrhart T, Brandner R (2018) Rolling shear: test configurations and properties of some European soft-and hardwood species. Eng Struct 172:554-572

EN 1995-1-1 (2004) Eurocode 5: design of timber structures-Part 1-1: general-common rules and rules for buildings. European Committee for Standardization, (CEN)

EN 338 (2009) Structural timber-strength classes. European Committee for Standardization, (CEN)

EN 408 (2010) Structural Timber and Glued Laminated Timber. Determination of some physical and mechanical properties. European Committee for Standardization, (CEN)

Farruggia F, Perré P (2000) Microscopic tensile tests in the transverse plane of earlywood and latewood parts of spruce. Wood Sci Technol 34(2):65-82

Gehri E (1997) Timber in compression perpendicular to the grain. IUFRO 502 Timber Engineering

Hall C (1980) Behaviour of wood under compression perpendicular to grain loading. $\mathrm{PhD}$ thesis, University of British Columbia

Hankinson R (1921) Investigation of crushing strength of spruce at varying angles of grain. Air Serv Inf Circ 3(259): 130

Hassel B, Berard P, Modén C, Berglund L (2009) The single cube apparatus for shear testing-full-field strain data and finite element analysis of wood in transverse shear. Compos Sci Technol 69(7-8):877-882

Hill R (1950) The mathematical theory of plasticity. Oxford University Press, London

Hoffman O (1967) The brittle strength of orthotropic materials. J Compos Mater 1(2):200-206 
Hoffmeyer P, Damkilde L, Pedersen T (2000) Structural timber and glulam in compression perpendicular to grain. Holz Roh Werkst 58(1):73-80

Iosipescu N (1967) New accurate procedure for single shear testing of metals. J Mater 2:537-566

Kasal B, Leichti RJ (2005) State of the art in multiaxial phenomenological failure criteria for wood members. Prog Struct Eng Mater $7(1): 3-13$

Kollmann FF, Kuenzi EW, Stamm AJ (2012) Principles of wood science and technology: II wood based materials. Springer, Berlin

Kristian BD (2009) Mechanical properties of clear wood from Norway spruce. PhD thesis, Norwegian University of Science and Technology, Faculty of Engineering Science and Technology, Department of Structural Engineering

Lathuilliere D, Pop O, Bléron L, Dubois F, Fouchal F, Bocquet J (2015) Spreading of transverse compressive stresses in glued laminated timber. Eur J Wood Prod 73(4):475-484

Leijten A, Jorissen A, De Leijer B (2012) The local bearing capacity perpendicular to grain of structural timber elements. Constr Build Mater 27(1):54-59

Mackenzie-Helnwein P, Eberhardsteiner J, Mang HA (2003) A multisurface plasticity model for clear wood and its application to the finite element analysis of structural details. Comput Mech 31(1-2):204-218

Madsen B, Hooley R, Hall C (1982) A design method for bearing stresses in wood. Can J Civil Eng 9(2):338-349

Magistris DF, Salmén L (2004) Combined shear and compression analysis using the Iosipescu device: analytical and experimental studies of medium density fiberboard. Wood Sci Technol 37(6):509-521

Magistris DF, Salmén L (2005) Combined shear and compression analysis using a modified Iosipescu shear test device. Experimental studies on dry wood. Holzforschung 59(5):539-545

Mascia NT, Simoni RA (2013) Analysis of failure criteria applied to wood. Eng Fail Anal 35:703-712

Melin N (2008) The modified Iosipescu shear test for orthotropic materials. PhD thesis, Department of Solid Mechanics, Royal Institute of Technology, Sweden

Mestek P (2011) Punktgestützte Flächentragwerke aus Brettsperrholz (BSP)-Schubbemessung unter Berücksichtigung von Schubverstärkungen (Cross laminated timber (CLT) plane structures under concentrated loading from point supports-shear design including reinforcements). PhD thesis, Technische Universität München (in German)

Norris CB (1962) Strength of orthotropic materials subjected to combined stresses. Misc Pub FPL-1816 Madison, Wis: US Dept of Agriculture, Forest Service, Forest Products Laboratory

Schellekens J, De Borst R (1990) The use of the Hoffman yield criterion in finite element analysis of anisotropic composites. Compu Struct 37(6): 1087-1096

SIA 265 (2012) Swiss Standard SN 505265 (SIA 265): Timber structures. Swiss Society of Engineers and Architects SIA, Zurich

Spengler R (1982) Festigkeitsverhalten von Brettschichtholz unter zweiachsiger Beanspruchung. 1. Ermittlung des Festigkeitsverhaltens von Brettelementen aus Fichte durch Versuche (Load-carrying behaviour of glued laminated timber subjected to biaxial loading; part 1: experimental determination of loadcarrying behaviour of spruce laminations). Technische Universität München (in German)

Steiger R, Gehri E (2011) Interaction of shear stresses and stresses perpendicular to the grain. In: International council for research and innovation in building and construction. Working commission W18-Timber structures, Meeting forty-four, Alghero, Italy, Paper 44-6-2

Stenberg N (2002) On the out-of-plane mechanical behaviour of paper materials. PhD thesis, Department of Solid Mechanics, Royal Institute of Technology, Sweden

Tabarsa T (1999) Compression perpendicular-to-grain behaviour of wood. PhD thesis, The University of New Brunswick, Canada

Tsai SW, Wu EM (1971) A general theory of strength for anisotropic materials. J Compos Mater 5(1):58-80

Van der Put T (2008) Derivation of the bearing strength perpendicular to the grain of locally loaded timber blocks. Holz Roh Werkst 66(6):409-417

Zhong W, Rusinek A, Jankowiak T, Huang X, Farid A (2015) Experimental and numerical investigation on compression orthotropic properties of spruce wood in axial and transverse loading directions. Eng Trans 62(4):381-401

Publisher's Note Springer Nature remains neutral with regard to jurisdictional claims in published maps and institutional affiliations. 